\title{
Crónica de la jurisprudencia del Tribunal de Justicia de la Unión Europea
}

\author{
Case Law Review of the Court of Justice of the European Union
}

\author{
David Ordóñez Solís \\ Magistrado y miembro de la Red de Expertos en Derecho \\ de la Unión Europea del Consejo General del Poder Judicial
}

doi: 10.18543/ced-55-2016pp195-234

Sumario: I. Introducción.-II. Primera parte. Los desarrollos jurisprudenciales del derecho de la Unión Europea 1. El espacio de libertad, seguridad y justicia: ciudadanos de la Unión y de terceros países. 1.1. Los derechos de los ciudadanos de la Unión. 1.2. Los derechos de los nacionales de terceros Estados. 1.3. La cooperación judicial penal y civil 2. El mercado único europeo. 2.1. La discriminación por la edad y los trabajadores. 2.2. Los derechos de los consumidores. 2.3. La contratación pública y la libre competencia. 2.4. La protección del medio ambiente.-III. Segunda parte. La jurisprudencia europea provocada por los jueces españoles y sus efectos en el derecho interno. 1. Las sentencias prejudiciales «españolas».1.1. Las respuestas sobre cláusulas abusivas: sentencias y autos. 1.2. La cooperación judicial civil y la traducción de los documentos: auto Alta Realitat. 1.3. El blanqueo de capitales y la financiación del terrorismo: sentencia Safe Interenvíos. 1.4. La compensación equitativa por los derechos de autor en el caso de copias privadas: sentencia EGEDA. 1.5. El alcance de la indemnización por vulneración de la propiedad intelectual: sentencia Liffers. 1.6. La prueba de medios de subsistencia en la agrupación familiar de extranjeros: sentencia Khachab. 1.7. La dimensión medioambiental de las ayudas europeas a la agricultura: sentencia Planes Bresco. 1.8. La indemnización por despido discriminatorio entre mujeres y hombres: sentencia Arjona Camacho. 1.9. Los permisos parental y de maternidad de los cooperativistas: sentencia Rodríguez Sánchez. 2. Las nuevas cuestiones prejudiciales «españolas» pendientes en el Tribunal de Justicia. 2.1. La Directiva sobre contratos de duración determinada y sus efectos en el empleo público español. 2.2. El régimen de ayudas de Estado y el cuestionamiento de los tributos autonómicos y locales. 3. Los incumplimientos medioambientales de España. - IV. Relación de las sentencias comentadas (Tribunal de Justicia y Tribunal General). 


\section{Introducción}

El 23 de junio de 2016 los británicos dijeron que se iban de la Unión Europea. Reino Unido seguirá, como es obvio, en Europa pero será un tercero en el proceso de integración. Ya no impedirá que la Unión Europea reafirme su vocación federal como se intentó recoger en el Tratado de Maastricht ni que la unión sea cada vez más estrecha entre los pueblos europeos como bien se dice desde el Tratado de Roma de 25 de marzo de 1957, que no negociaron ni firmaron en ese momento los británicos. Pero no hay duda de que también el Reino Unido será un país privilegiado para la Unión Europea, un socio que tanto aportó desde dentro y que tanto debe contribuir desde fuera para hacer de Europa un continente más próspero y más acogedor para sus ciudadanos.

¡Cuánto echaremos de menos la participación de los jueces británicos en la creación de un espacio judicial europeo! Ciertamente, los jueces del Reino Unido seguirán aplicando el Derecho europeo, probablemente el mismo Derecho del Espacio Económico Europeo interpretado, paradojas de la vida, desde el mismo Luxemburgo por el Tribunal de la EFTA pero subordinado a la jurisprudencia del Tribunal de Justicia de la Unión Europea en el que ya, lamentablemente, los jueces británicos no podrán contribuir con tanta prudencia y sentido común como hasta ahora.

Estos hechos tan penosos para el proceso de integración no han impedido que el Tribunal de Justicia de la Unión Europea siga tratando de reacomodar su estructura e intentando culminar una etapa de transición para reducirse a dos niveles: el Tribunal de Justicia, cada vez más un tribunal de casación, y el Tribunal General, con funciones reales de primera instancia.

Ahora bien, la verdadera casación en la Unión Europea se consigue, en realidad, a través de los reenvíos prejudiciales de los jueces nacionales que resuelve el Tribunal de Justicia. En cambio, el control de la legalidad de los actos de las instituciones europeas, cuya competencia exclusiva corresponde al Tribunal de Luxemburgo, queda encomendado al Tribunal General.

Así lo confirman, una vez más, las estadísticas de 2015 del Tribunal de Justicia: se registraron 713 asuntos y concluyeron 616; más del 60\% de los asuntos fueron cuestiones prejudiciales (436), el 29\% de los asuntos correspondió a los recursos de casación respecto de sentencias del Tribunal General (206) y menos del $10 \%$ consistió en recursos por incumplimiento (37).

En respuesta a cuestiones prejudiciales, el Tribunal de Justicia dictó 296 sentencias y 47 autos, procedimiento este último cada vez más utilizado cuando las preguntas de los jueces nacionales tienen, desde el punto de vista del Derecho de la Unión, una solución bastante fácil, lo que flexi- 
biliza y agiliza la cooperación entre los jueces nacionales y el Tribunal de Justicia.

Las materias abordadas por las cuestiones prejudiciales se referían, de manera destacada, al espacio de libertad, seguridad y justicia (50), a la fiscalidad (43) y a la protección de los consumidores (39).

La media del tiempo necesario para resolver un reenvío prejudicial sigue en torno a los 15,3 meses. No obstante, en determinados supuestos se aplica el procedimiento prejudicial de urgencia (PPU) de manera que en menos de dos meses pueden llegar a resolverse las dudas del juez nacional; no obstante, es comprensible que de las 11 solicitudes de los jueces nacionales para seguir este trámite privilegiado, el Tribunal de Justicia solo accedió en cinco supuestos.

Después de los últimos ajustes, la presencia «española» en Luxemburgo es particularmente prestigiosa. Por una parte, la abogada del Estado, Rosario Silva de Lapuerta, sigue como juez en el Tribunal de Justicia; y el magistrado del Tribunal Supremo, Manuel Campos Sánchez-Bordona, acaba de incorporarse como abogado general. En el Tribunal General fue nombrado como juez Leopoldo Calvo-Sotelo Ibáñez-Martín, letrado del Consejo de Estado, que se une al otro juez español, Ignacio Ulloa Rubio, de la carrera judicial.

La jurisprudencia sigue desarrollándose en los ámbitos tradicionales por lo que destacaré únicamente algunas de las resoluciones judiciales más relevantes del primer semestre de 2016, tratando de ser más exhaustivo con la jurisprudencia provocada desde España.

\section{Primera parte. Los desarrollos jurisprudenciales del derecho de la Unión Europea}

Los derechos de las personas, de los ciudadanos de la Unión y de los nacionales de terceros países, son en estos momentos la preocupación máxima en la integración europea; la crisis de los refugiados ha puesto de manifiesto que Europa no solo se preocupa de las mercancías y de los capitales sino que también lo hace, no siempre con fortuna, respecto de las personas. Esto no impide reconocer que el mercado europeo constituye la base de las libertades económicas fundamentales hasta el punto de que cuestiones tan relevantes como la contratación pública o la protección de los consumidores siguen ocupando gran parte de la energía desplegada por el Tribunal de Justicia en su jurisprudencia.

Por eso, esta primera parte la ordeno en torno a lo que constituyen los dos logros de la integración europea: por una parte, el novedoso espacio europeo de libertad, seguridad y justicia que en los últimos 20 años ha ad- 
quirido un desarrollo legislativo y jurisprudencial espectacular; y, por otra parte, el tradicional mercado único europeo que sigue perfeccionándose legislativa y jurisprudencialmente.

En ambos caso las respuestas del Tribunal de Justicia contienen un recordatorio a los jueces nacionales de los principios que informan las relaciones entre el Derecho de la Unión y los Derechos nacionales, e insisten en las consecuencias de la primacía, del efecto directo y de la responsabilidad. De hecho, en la sentencia Puligienica Facility Esco (PFE) (C-689/13) el Tribunal de Justicia ha tenido que recordar la primacía, deducida de la jurisprudencia Simmenthal (106/77, EU:C:1978:49), del Derecho de la Unión frente al carácter vinculante de determinada jurisprudencia interna, en este caso una sentencia del italiano Consejo de Estado que contenía una jurisprudencia que resultaba contraria a una sentencia posterior del Tribunal de Justicia.

El Tribunal administrativo de apelación de Sicilia le preguntaba a Luxemburgo qué tenía que hacer en ese caso frente a la jurisprudencia vinculante procedente de Roma. La respuesta del Tribunal de Justicia no puede ser más clara: «sería incompatible con las exigencias inherentes a la propia naturaleza del Derecho de la Unión toda disposición de un ordenamiento jurídico nacional o toda práctica, legislativa, administrativa o judicial, que redujese la eficacia del Derecho de la Unión al negar al juez competente para aplicar ese Derecho la facultad de hacer, en el mismo momento de esa aplicación, todo lo necesario para excluir las disposiciones legislativas nacionales que pudiesen constituir un obstáculo a la plena eficacia de las normas de la Unión».

\section{El espacio de libertad, seguridad y justicia: ciudadanos de la Unión $y$ de terceros países}

La crisis de los refugiados ha puesto en jaque la propia integración europea: a las instituciones de la Unión, a los Estados miembros y, en definitiva, al propio proyecto de integración europea. Los carteles de la campaña a favor del Brexit mostrando la invasión extranjera de Inglaterra pasarán a la historia universal de la infamia política.

Lo cierto es que la labor del Tribunal de Justicia sigue siendo la de hacer cosas con casos, la de proteger los derechos tal como se recogen en la Carta de los Derechos Fundamentales de la Unión y tal como se desarrollan en los reglamentos y en las directivas de la Unión Europea.

Estadísticamente es este el ámbito más importante que ocupa en el último lustro al Tribunal de Justicia y por eso merece atención ordenándola en torno a los derechos de los ciudadanos de la Unión, los derechos de los 
nacionales de terceros países y en torno a la cooperación judicial penal y civil.

\subsection{Los derechos de los ciudadanos de la Unión}

La crisis económica también está influyendo en la jurisprudencia del Tribunal de Justicia. Lo que antes era un desarrollo expansivo de los derechos de los ciudadanos de la Unión, ahora está suponiendo la introducción de matices y, en definitiva, de restricciones. Es verdad, no obstante, que también las libertades de la Unión Europea se pueden utilizar abusivamente en ámbitos tan sensibles como la protección laboral y social.

La sentencia García-Nieto (C-299/14) supone una concepción restrictiva de la libre circulación de los trabajadores en la medida en que la no discriminación en que se basa se puede restringir por cada Estado miembro para aquellos supuestos en que el ciudadano llega al país buscando trabajo durante los tres primeros meses.

El Tribunal regional de Renania del Norte-Westfalia le planteó al Tribunal de Justicia, en un asunto que enfrentaba a una familia de españoles, una pareja y dos hijos, por el cobro de las prestaciones de subsistencia de la Seguridad Social alemana. La cuestión se refería únicamente al cónyuge y a un hijo de este que fueron a Alemania a reunirse con su esposa y madre de otro hijo. En primera instancia, el tribunal alemán dio la razón a la familia española; pero en apelación el tribunal regional planteó varias cuestiones prejudiciales.

Durante la tramitación de este procedimiento prejudicial el Tribunal de Justicia se había pronunciado en la sentencia Dano (C-333/13, EU:C:2014:2358) y ahora con esta sentencia García-Nieto el Tribunal de Luxemburgo completa el régimen aplicable únicamente a quienes no sean trabajadores por cuenta ajena o por cuenta propia durante los tres primeros meses de su residencia en el Estado de acogida.

El Tribunal de Justicia se basa en la jurisprudencia previa (sentencia Alimanovic, C-67/14, EU:C:2015:597) conforme a la cual la Directiva 2004/38 establece un sistema gradual de mantenimiento de la condición de trabajador que pretende asegurar el derecho de residencia y el acceso a las prestaciones sociales, toma en consideración diferentes factores que caracterizan la situación particular de cada solicitante de una prestación social y, en especial, la duración del ejercicio de una actividad económica.

El razonamiento que emplea el Tribunal de Justicia es el siguiente: en la medida en que las autoridades nacionales no pueden exigir que los ciudadanos de la Unión posean medios de subsistencia suficientes y una cobertura médica personal cuando realizan una estancia de tres meses de duración como máximo en sus respectivos territorios, es legítimo no obligar a 
dichas autoridades nacionales a hacerse cargo de esos ciudadanos durante ese tiempo.

En cambio, en la sentencia Benallal (C-161/15) el Tribunal de Justicia responde una cuestión prejudicial planteada por el belga Consejo de Estado en un litigio que enfrentaba a Bensada Benallal, de nacionalidad española, con las autoridades belgas que le habían revocado la autorización de residencia. Ante la instancia administrativa suprema de Bélgica se planteaba si el recurrente podía invocar, en particular y por primera vez, el motivo de anulación consistente en la violación del derecho fundamental a ser oído.

A tal efecto, el Tribunal de Justicia considera que, en virtud del principio de autonomía, corresponde al ordenamiento jurídico interno de cada Estado miembro establecer las reglas de los recursos administrativos y judiciales siempre y cuando no sean menos favorables que aquellas que se aplican a situaciones similares de derecho interno (principio de equivalencia) y no impidan en la práctica o hagan excesivamente difícil el ejercicio de los derechos conferidos por el derecho de la Unión (principio de efectividad).

Pues bien y en este caso el Tribunal de Justicia considera que la cuestión está en si se cumple el principio de equivalencia, es decir, si el Consejo de Estado puede conocer de motivos de impugnación invocados por primera vez en casación siempre y cuando afecten al orden público interno.

El Tribunal de Justicia le recuerda al supremo tribunal administrativo belga que el respeto de los derechos de defensa constituye un principio fundamental del Derecho de la Unión que debe ser protegido incluso en el caso de que no haya ninguna regulación sobre el procedimiento.

\subsection{Los derechos de los nacionales de terceros Estados}

En 2015 y en 2016 la crisis de los refugiados ha revelado las debilidades de la propia integración europea. Pero al mismo tiempo el Tribunal de Justicia no ha dejado de interpretar el alcance del control de los nacionales de terceros países en la Unión Europea y lo ha hecho, por lo general, convocando la Gran Sala, que se pronuncia sobre la legalidad europea de los internamientos, la prisión y otras limitaciones a la libertad de los extranjeros en la Unión Europea.

La sentencia J.N. (C-601/15 PPU) fue dictada por la Gran Sala del Tribunal de Justicia a petición del holandés Consejo de Estado, que cuestionaba la validez de la previsión de la Directiva 2013/33/UE respecto de los internamientos, más en particular el internamiento de un solicitante de asilo cuando lo exige la protección de la seguridad nacional o del orden público. En menos de tres meses se pronunció el Tribunal de Justicia a través del procedimiento prejudicial de urgencia. 
J.N. había entrado en los Países Bajos y tenía un abultado historial delictivo de numerosos robos al tiempo que había solicitado reiteradamente el derecho de asilo. Después de cumplir prisión fue internado para ser expulsado.

Para determinar la validez de la Directiva en cuanto al internamiento por razones de seguridad nacional o de orden público, el Tribunal de Justicia tiene en cuenta que la jurisprudencia del Tribunal Europeo de Derechos Humanos ha resuelto que el internamiento de un solicitante de asilo es contrario al Convenio Europeo de Derechos Humanos cuando no se acuerde en orden a la expulsión.

Ahora bien, el Tribunal de Justicia establece una puntualización muy relevante conforme a la cual, si bien los derechos fundamentales reconocidos por el Convenio Europeo de Derechos Humanos forman parte del Derecho de la Unión como principios generales, el Convenio Europeo no constituye, dado que la Unión no se ha adherido a él, un instrumento jurídico integrado formalmente en el ordenamiento jurídico de la Unión. Esto quiere decir que la validez de la Directiva debe basarse únicamente en los derechos fundamentales garantizados por la Carta de los Derechos Fundamentales de la Unión.

Por una parte, el Tribunal de Justicia examina con detalle la limitación al derecho a la libertad consistente en autorizar el internamiento de un solicitante de asilo cuando lo exige la protección de la seguridad nacional o del orden público. Según dispone la Carta, cualquier limitación del ejercicio de los derechos y libertades reconocidos deberá ser establecida por la ley y habrá de respetar el contenido esencial de dichos derechos y libertades.

En primer lugar, la limitación está contenida en la Directiva, en un acto legislativo de la Unión. En segundo lugar, el internamiento no afecta al contenido esencial del derecho a la libertad pues no cuestiona la garantía de ese derecho y solo confiere a los Estados miembros la facultad de internar a un solicitante de asilo debido a su comportamiento individual y en las circunstancias excepcionales previstas. En tercer lugar, la protección de la seguridad nacional y del orden público contribuye también a la protección de los derechos y de las libertades de los demás, dado que la Carta establece el derecho de todas las personas no solo a la libertad sino también a la seguridad. Por último, el internamiento supera el test de proporcionalidad dado que la Directiva 2013/33 establece que los Estados miembros velarán por que el Derecho nacional establezca normas que ofrezcan alternativas al internamiento, como la presentación periódica ante las autoridades, el depósito de una fianza o la obligación de permanecer en un lugar determinado.

Por otra parte, el Tribunal de Justicia determina claramente los requisitos de los internamientos: no pueden internar a una persona por la única razón de que sea un solicitante de protección internacional; el período de 
internamiento del solicitante debe ser lo más breve posible; la decisión de internamiento debe indicar por escrito los motivos de hecho y de Derecho en los que se basa y deben comunicarse por escrito determinadas informaciones al solicitante, al menos, en una lengua que comprenda.

Por otra parte, el Tribunal de Justicia se refiere a la justificación por razones de orden público («la perturbación del orden social que constituye cualquier infracción de la ley, que exista una amenaza real, actual y suficientemente grave que afecte a un interés fundamental de la sociedad») y de seguridad pública («el hecho de poner en peligro el funcionamiento de las instituciones y de los servicios públicos esenciales, así como la supervivencia de la población, además del riesgo de una perturbación grave de las relaciones exteriores o de la coexistencia pacífica de los pueblos, o, incluso, la amenaza a intereses militares»).

En consecuencia, el Tribunal de Justicia considera justificado el internamiento de JN dados los delitos cometidos en Holanda y por haber sido objeto de una decisión de abandonar dicho territorio, acompañada de una prohibición de entrada de una duración de diez años, que adquirieron firmeza.

Por último, el Tribunal de Justicia, a pesar de las prevenciones sobre la aplicación del Convenio Europeo de Derechos Humanos, no duda en aplicar la jurisprudencia del Tribunal de Estrasburgo de la que deduce, en sustancia, que la Directiva es conforme con tal jurisprudencia.

En suma, el Tribunal de Justicia llega a la conclusión de la validez del internamiento previsto en la Directiva sobre asilo y de la legalidad europea de la actuación de las autoridades neerlandesas en relación con el ciudadano que provenga de un país tercero.

La sentencia Affum (C-47/15) le permite a la Gran Sala del Tribunal de Justicia llegar a la conclusión de que no puede imponerse una pena de prisión por la entrada irregular de un extranjero en Francia en la medida en que sería contrario a la Directiva 2008/115/CE relativa a normas y procedimientos comunes en los Estados miembros para el retorno de los nacionales de terceros países en situación irregular.

Sélina Affum había entrado de manera irregular en Francia procedente de Bélgica, dentro del espacio Schengen, y con destino a Londres, fuera del espacio de Schengen. El Tribunal de Justicia, a preguntas del Tribunal de Casación francés, consideró que esta ciudadana ghanesa estaba en situación irregular en Francia y que se le aplicaba la Directiva 2008/115/CE por no cumplir las condiciones de entrada, de estancia o de residencia.

Esta misma Directiva permite un procedimiento de retorno cuyas fases se desarrollan conforme a una graduación de las medidas que han de tomarse para la ejecución de la decisión de retorno, y, si se trata de una privación de libertad, permite, a lo sumo, el internamiento en un centro es- 
pecializado con objeto de asegurar el respeto de los derechos fundamentales de los nacionales de los terceros países afectados.

En cambio, la misma Directiva no permite que se encarcele a los extranjeros de terceros países cuando el procedimiento de retorno establecido en la Directiva 2008/115 no haya terminado, ya que tal medida puede frustrar la aplicación del procedimiento y demorar el retorno, privando a dicha Directiva de su efecto útil.

Sin embargo, así como no es posible el castigo con pena de prisión por la entrada irregular, la Directiva no impide la pena de prisión de los extranjeros que hayan quebrantado una prohibición de entrada. En efecto, el Tribunal de Justicia considera que en el caso de cruce no autorizado de las fronteras exteriores fuera de los pasos fronterizos y de las horas de apertura establecidas el Código de fronteras Schengen los Estados miembros pueden fijar sanciones aunque estas no tienen que consistir en penas de prisión. En el caso de la ghanesa no se había producido tal infracción por lo que no cabría su encarcelamiento por el mero hecho de la entrada ilegal por una frontera interior desencadenante de una situación irregular cuando el procedimiento de retorno previsto por la Directiva aún no había finalizado o cuando otro Estado, como Bélgica, habría podido hacerse cargo de la extranjera, en aplicación de un acuerdo internacional concluido entre Francia y Bélgica.

También en su formación de Gran Sala el Tribunal de Justicia se pronunció sobre el derecho de asilo y la movilidad de los refugiados en la sentencia Alo (C-443/14 y C-444/14) en respuesta a dos cuestiones prejudiciales procedentes del Tribunal Supremo administrativo alemán.

Los ciudadanos sirios Ibrahim Alo y Amira Osso habían solicitado en 1999 y 2001 asilo en Alemania pero solo se les reconoció el estatuto de protección subsidiaria y se les exigió que residiesen en la región de Hannover. La cuestión básica es si esta limitación a la libre residencia en Alemania es conforme con la legislación europea aplicable, en particular, la Directiva 2011/95.

El Tribunal de Justicia llega a la conclusión de que esta Directiva debe interpretarse en el sentido de que los Estados de la Unión deben permitir a los beneficiarios de protección internacional tanto desplazarse libremente por el territorio del Estado miembro que les ha concedido dicha protección como escoger su lugar de residencia. No obstante, el Tribunal de Justicia admite que se imponga una obligación de residencia a un beneficiario del estatuto de protección subsidiaria que perciba determinadas prestaciones sociales específicas con el objetivo de facilitar la integración de los nacionales de terceros países en el Estado miembro que le ha concedido dicha protección.

En su formación de Gran Sala el Tribunal de Justicia se pronunció en su sentencia Ghezelbash (C-63/15) a requerimiento del Tribunal de Primera 
Instancia de La Haya sobre los límites que impone el derecho de tutela judicial efectiva de los extranjeros en relación con el sistema de asilo establecido en el denominado Reglamento Dublín III.

En este caso un iraní impugnaba en vía judicial una resolución administrativa que le denegaba la autorización de residencia como refugiado porque el Estado miembro responsable de examinar su solicitud de asilo era Francia. Al acudir al juez holandés, este la plantea al Tribunal de Justicia si este solicitante de asilo podía invocar, en el recurso interpuesto contra la decisión de trasladarlo, la aplicación errónea de un criterio de responsabilidad establecido en el artículo 12 del Reglamento (UE) n..$^{\circ}$ 604/2013 por el que se establecen los criterios y mecanismos de determinación del Estado miembro responsable del examen de una solicitud de protección internacional presentada en uno de los Estados miembros por un nacional de un tercer país o un apátrida.

El Tribunal de Justicia examina, por una parte, la importancia que tiene el derecho a la tutela judicial efectiva en el sistema de Dublín, modificado precisamente por el Reglamento 604/2013 que ha reforzado diferentes derechos y mecanismos que garantizan la participación de los solicitantes de asilo en el proceso de determinación del Estado miembro responsable: un derecho a la información del solicitante que recae, en particular, sobre los criterios para determinar el Estado miembro responsable y la jerarquía de esos criterios, incluido el hecho de que una solicitud de protección internacional presentada en un Estado miembro puede tener como consecuencia que ese Estado miembro se convierta en responsable, aun cuando esa responsabilidad no se base en dichos criterios; una entrevista personal con el solicitante de asilo debiendo garantizar el acceso del solicitante o su abogado al resumen de la entrevista que en determinados supuestos puede obviarse; y unas garantías de procedimiento en las modalidades de notificación de las decisiones de traslado y las normas aplicables a los recursos que pueden interponerse contra esas resoluciones, incluida la suspensión cautelar y la asistencia jurídica. Por tanto, los solicitantes de asilo deben ser asociados al procedimiento de determinación del Estado responsable y obliga a los Estados miembros a informarles de los criterios de responsabilidad y a ofrecerles la oportunidad de facilitar la información que permita la correcta aplicación de esos criterios, garantizándoles un derecho de recurso efectivo contra la decisión de traslado.

Por otra parte, el Tribunal de Justicia subraya que la nueva legislación pretende aumentar la eficacia del sistema de Dublín y la protección concedida a los solicitantes, protección garantizada mediante la tutela judicial de la que disfrutan. Esto supone que corresponde al tribunal que conoce del recurso comprobar si se han aplicado correctamente los criterios de responsabilidad establecidos por el legislador de la Unión y no debe confiar la res- 
ponsabilidad del examen a la conveniencia del solicitante. Para que no haya riesgo de retraso en la ejecución de las decisiones de traslado, el legislador de la Unión reconoce que los Estados miembros pueden decidir que la interposición de un recurso contra una decisión de traslado no sea suficiente, en sí misma, para suspender el traslado, de modo que éste puede tener lugar sin esperar al examen del recurso, siempre que no se haya solicitado la suspensión o que haya sido desestimada.

Por tanto, a juicio del Tribunal de Justicia un solicitante de asilo puede invocar, en un recurso interpuesto contra la decisión de trasladarlo, la aplicación errónea de un criterio de responsabilidad del examen de la solicitud de asilo.

En la sentencia Karim (C-155/15) se aborda el problema del control judicial de la determinación del Estado miembro responsable de examinar la petición de asilo. En este caso el Tribunal Superior de Inmigración de Suecia le preguntó al Tribunal de Justicia en relación con un sirio que previamente había estado en Eslovenia.

A juicio del Tribunal de Justicia, Suecia, ante la que se presentó la nueva solicitud de asilo, está obligada a llevar a término el proceso de determinación del Estado miembro responsable del examen de esta nueva solicitud y de hecho este nuevo proceso es diferente del que llevó a cabo inicialmente Eslovenia ante la que se presentó la primera solicitud de asilo y puede dar lugar a la designación de un nuevo Estado miembro responsable, por ejemplo si el Sr. Karim logra acreditar que abandonó el territorio de la Unión Europea durante un período de al menos tres meses. Por tanto, el tribunal ante el que se haya recurrido la decisión de traslado debe tener la posibilidad de examinar las alegaciones de un solicitante de asilo.

La sentencia Mirza (C-695/15 PPU) se refiere a un pakistaní que había entrado ilegalmente, procedente de Serbia, en Hungría donde había solicitado el asilo pero abandonó este país con destino a Austria siendo detenido en la República Checa. Readmitido por las autoridades húngaras, estas inadmitieron su solicitud y ordenaron su expulsión. El tribunal húngaro al que recurrió el Sr. Mirza le pregunta al Tribunal de Justicia sobre la interpretación del Reglamento (UE) n. ${ }^{\circ}$ 604/2013 (Reglamento Dublín III).

El Tribunal de Justicia resuelve en poco menos de tres meses la cuestión prejudicial señalando, en primer lugar, que un solicitante de asilo, como el Sr. Mirza en Hungría, no puede obtener ventajas si huye a la República Checa sin esperar a que su solicitud sea definitivamente resuelta por lo que de ser readmitido podría ser enviado a un país como Serbia considerado seguro por las autoridades húngaras y sin que sea relevante que tales detalles hubiesen sido comunicados por Hungría a la República Checa.

El Tribunal de Justicia interpreta que el Reglamento Dublín III reconoce del derecho del solicitante a que se adopte una decisión final sobre su 
solicitud de protección internacional, bien en el marco del procedimiento que se interrumpió o bien en un nuevo procedimiento que no debe considerarse referido a una solicitud posterior. Con esto se pretende garantizar al solicitante un examen de su solicitud que responda a las exigencias de la Directiva 2013/32 sobre procedimientos comunes para conceder o retirar el estatuto de protección internacional pero no prescribe la manera en la que el procedimiento debe reanudarse ni priva a Hungría de la posibilidad de declarar inadmisible la solicitud de asilo.

En fin, también la Gran Sala del Tribunal de Justicia dictó la sentencia Genc (C-561/14), a requerimiento de un tribunal de apelación danés, sobre la reagrupación familiar de nacionales turcos. Para el Tribunal de Justicia la decisión danesa constituye una «nueva restricción» que no está justificada en la medida en que supedita la reagrupación familiar entre un trabajador turco con residencia legal y su hijo menor al requisito de que este último presente o pueda presentar un arraigo suficiente para permitirle una integración satisfactoria y de que la solicitud de reagrupación familiar se presente más de dos años después de haber obtenido el permiso de residencia por tiempo indefinido o con posibilidad de residencia permanente.

\subsection{La cooperación judicial penal y civil}

La ampliación de la Unión Europea a 28 Estados miembros ha supuesto pasar de una cierta homogeneidad inicial, de los seis de los años 60 o los nueve en los años 70, a una heterogeneidad en las siguientes ampliaciones hacia el Sur y hacia el Este de Europa. De hecho, las últimas ampliaciones ya en el siglo XXI, con la incorporación de países con graves problemas económicos y de protección de los derechos fundamentales explican que la jurisprudencia del Tribunal de Justicia sea sumamente cautelosa y que, del mismo modo que constata extraordinarias diferencias económicas, observe distintos niveles de protección de los derechos fundamentales.

Esto es lo que ocurre a la hora del aplicar tanto la orden europea de detención y entrega en el ámbito de la cooperación judicial penal como el sistema de reconocimiento mutuo de resoluciones judiciales civiles.

Por lo que se refiere a la cooperación judicial penal, resulta de gran interés la sentencia Aranyosi y Căldăraru (C-404/15 y C-659/15 PPU) donde el Tribunal de Justicia en su composición de Gran Sala se pronunció sobre el procedimiento a seguir cuando existe riesgo real de trato inhumano o degradante debido a las condiciones de detención de la persona afectada en Hungría y Rumanía, cuyos tribunales había emitido la orden europea de detención y entrega.

En este supuesto el Tribunal regional penal de Bremen le pedía al Tribunal de Justicia que interpretase la Decisión Marco 2002/584/JAI sobre la 
euroorden en relación con dos órdenes de detención y entrega emitidas por jueces húngaros y rumanos a las que ante el tribunal alemán los nacionales húngaro y rumano se habían opuesto alegando que en las respectivas cárceles de Hungría y Rumanía ser verían vulnerados sus derechos fundamentales.

En su respuesta el Tribunal de Justicia recuerda su reiterada jurisprudencia conforme a la cual la euroorden se basa en la confianza y en el reconocimiento mutuos. La razón de ser de este procedimiento es, por una parte, «a través del establecimiento de un nuevo sistema simplificado y más eficaz de entrega de personas condenadas o sospechosas de haber infringido la ley penal, facilitar y acelerar la cooperación judicial de cara a la consecución del objetivo atribuido a la Unión de llegar a ser un espacio de libertad, seguridad y justicia basado en el grado de confianza elevado que debe existir entre los Estados miembros». Y, por otra parte, el Tribunal de Justicia insiste en el principio de reconocimiento mutuo que se basa «en la confianza recíproca entre los Estados miembros en que sus respectivos ordenamientos jurídicos nacionales están en condiciones de proporcionar una protección equivalente y efectiva de los derechos fundamentales, reconocidos en el ámbito de la Unión, en particular en la Carta».

No obstante, estos principios de confianza recíproca y de reconocimiento mutuo pueden limitarse en circunstancias excepcionales, es decir, cuando se ponga en peligro el respeto de los derechos fundamentales tal como se hallan consagrados en la Carta.

A partir de esta excepción el Tribunal de Justicia explica cómo debe proceder un tribunal de ejecución de la euroorden en el caso de que se le haya alegado la eventual vulneración de los derechos fundamentales, por ejemplo el que prohíbe las penas o los tratos inhumanos o degradantes dado que tiene carácter absoluto y es indisociable del respeto de la dignidad humana.

En primer lugar, el juez de ejecución de la euroorden, es decir el juez alemán, deberá apreciar la existencia del riesgo del torturas o malos tratos a la hora de pronunciarse sobre la entrega a los jueces húngaros y rumanos, porque la ejecución de dicha orden no puede dar lugar a que se trate de forma inhumana o degradante a esa persona. Para ello, el Tribunal de Justicia le ofrece unos parámetros fiables: resoluciones judiciales internacionales, como las sentencias del Tribunal Europeo de Derechos Humanos, resoluciones judiciales del Estado miembro emisor o decisiones, informes u otros documentos elaborados por los órganos del Consejo de Europa o del sistema de las Naciones Unidas.

En segundo lugar, el juez de ejecución de la euroorden también debe comprobar si existen razones serias y fundadas para creer que esa persona, tras ser entregada, por ejemplo a Hungría o Rumanía, correrá un riesgo real 
de sufrir un trato inhumano o degradante. Esa comprobación exige que el juez de ejecución solicite a la autoridad judicial del Estado miembro emisor la transmisión urgente de toda la información complementaria necesaria sobre las condiciones de reclusión previstas para la persona de que se trate en ese Estado miembro.

En tercer lugar, si se cumplen las condiciones anteriores el juez deberá aplazar la ejecución de esa orden, pero también el Estado miembro de ejecución está obligado a informar a Eurojust de las causas de la demora. Para el caso de que persista la situación el juez de ejecución de la euroorden debe tener en cuenta que la emisión de una orden de detención europea no puede justificar que se mantenga en detención a la persona de que se trate sin límite temporal alguno hasta el punto de que, si la existencia del riesgo no puede excluirse en un plazo razonable, la autoridad deba decidir si procede poner fin al procedimiento de entrega.

También en el marco de la cooperación judicial penal la sentencia Dworzecki (C-108/16 PPU) interpreta la Decisión Marco 2002/584/JAI, modificada en 2009 , relativa a la orden de detención europea y a los procedimientos de entrega entre Estados miembros y aclara, exactamente en tres meses, las dudas de un tribunal de Ámsterdam que había recibido la solicitud de la euroorden de un tribunal polaco respecto del ciudadano polaco, Paweł Dworzecki, residente en Holanda.

En este el caso el tribunal holandés pregunta al Tribunal de Justicia sobre la conformidad de la Decisión marco con la sentencia de 1 de marzo de 2006, Sejdovic c. Italia, del Tribunal Europeo de Derechos Humanos (CE:ECHR:2006:0301JUD005658100) en relación con la exigencia de que el acusado haya tenido conocimiento suficiente de las investigaciones y de las acusaciones que se hayan hecho.

Por una parte, el Tribunal de Justicia considera que constituyen nociones autónomas del Derecho de la Unión las expresiones contenidas en la Decisión marco conforme a las cuales el tribunal de ejecución puede denegar la entrega si el imputado, con suficiente antelación, no fue citado en persona e informado así de la fecha y el lugar previstos para el juicio del que se deriva esa resolución, o bien recibió efectivamente por otros medios, de tal forma que pueda establecerse sin lugar a dudas que tenía conocimiento de la celebración prevista del juicio, información oficial de la fecha y lugar previstos para el mismo.

En sus razonamientos el Tribunal de Justicia insiste en que, con el fin de no obstaculizar la cooperación judicial europea, el legislador de la Unión consideró necesario prever motivos de no reconocimiento precisos y comunes de decisiones de detención dictadas en un proceso en el que la persona afectada no hubiese comparecido sin necesidad de establecer una regulación de las formas y de las modalidades teniendo en cuenta las exigencias 
procedimentales de los derechos nacionales con el fin de alcanzar la finalidad de la Decisión marco.

Por otra parte y al interpretar tales expresiones, el Tribunal de Justicia llega a la conclusión de que en determinados supuestos algunas citaciones no cumplen los requisitos exigidos en la Decisión marco. A tal efecto, el Tribunal de Justicia tiene en cuenta que el derecho a un juicio justo de una persona que haya sido citada para comparecer ante un tribunal penal exige que se le haya informado para poder organizar de manera eficaz su defensa. Por tanto, la citación debe asegurar que el interesado ha recibido con antelación suficiente la información sobre la fecha y el lugar del juicio de tal modo que permita al tribunal de ejecución de la orden de detención comprobar que se han respetado sus derechos de defensa.

En el caso concreto y no habiendo habido una citación personal la citación a través de un tercero exige que resulte acreditado de manera inequívoca que la tercera persona la ha entregado efectivamente al interesado. A tal efecto, el tribunal de emisión puede indicar tales circunstancias en la orden de detención o certificarlas convenientemente y el tribunal de ejecución puede basarse en cualesquiera otras circunstancias, por ejemplo resultado de la audiencia del propio interesado, para comprobar tal extremo o incluso puede solicitar por vía urgente informaciones complementarias.

En el ámbito de la cooperación judicial civil, la sentencia Meroni (C559/14) permite al Tribunal de Justicia interpretar el Reglamento (CE) n. ${ }^{\circ} 44 / 2001$ relativo a la competencia judicial, el reconocimiento y la ejecución de resoluciones judiciales en materia civil y mercantil y determinar, en particular, el alcance del derecho a la tutela judicial efectiva aplicable en estos procedimientos.

El Tribunal Supremo letón le preguntó al Tribunal de Justicia si podía denegar la ejecución de un auto de medidas cautelares dictado por la High Court of Justice de Londres sin haber oído a un tercero interesado ante el tribunal comercial británico.

El Tribunal de Justicia recuerda la consagración por el artículo 47 de la Carta de los Derechos Fundamentales de la Unión del derecho a la tutela judicial efectiva que se aplica en los supuestos regulados por el Reglamento (CE) n. $.^{\circ} 44 / 2001$ de cooperación judicial civil, por tanto una violación de tal derecho constituiría una causa de orden público susceptible de determinar la denegación de la ejecución de la resolución judicial del tribunal de otro Estado miembro.

Ahora bien, dado que la cooperación judicial civil y, en particular, el Reglamento (CE) n. ${ }^{\circ} 44 / 2001$ se basan en la confianza recíproca en la justicia dentro de la Unión, los justiciables están obligados a utilizar todas las vías de recurso que el Derecho del Estado miembro de origen les brinda antes de que sea necesario invocar la violación del orden público. 
En este sentido, a juicio del Tribunal de Justicia, el tribunal letón no puede apreciar la existencia de los eventuales derechos que un tercero, en este caso el Sr. Meroni, que no fue parte en el procedimiento incoado ante el tribunal londinense, invoca para oponerse al reconocimiento y a la ejecución de la resolución extranjera. Esto es así porque el tribunal letón podría verse impulsado a examinar la fundamentación del auto procedente de Londres lo cual sería manifiestamente contrario al Reglamento n. ${ }^{\circ} 44 / 2001$ que impide la revisión de la resolución judicial extranjera en cuanto al fondo.

\section{El mercado único europeo}

El mercado único es la base de la integración europea hasta el punto de que sigue produciendo efectos de extraordinarias consecuencias en los ámbitos de las libertades económicas fundamentales. Las sentencias elegidas responden a ámbitos clásicos como la discriminación laboral por razón de la edad, los derechos de los consumidores, la contratación pública, la aplicación administrativa de la libre competencia y, en fin, la protección del medio ambiente.

\subsection{La discriminación por la edad y los trabajadores}

La sentencia DI (C-441/14) es la respuesta del Tribunal de Justicia a la pregunta del Tribunal Supremo danés sobre si el principio general del Derecho de la Unión relativo a la prohibición de discriminación por razón de la edad puede ser invocado por un trabajador contra un empresario para obligarle a pagar una indemnización por despido establecida en el Derecho danés, aun cuando dicho empresario, de conformidad con el Derecho nacional, estuviese exento de ese pago. En realidad, el tribunal danés preguntaba en qué medida un principio no escrito del Derecho de la Unión puede oponerse a que un empresario particular pueda invocar un precepto legislativo nacional contrario a dicho principio.

La respuesta del Tribunal de Justicia no puede ser más contundente recordando su jurisprudencia sobre la primacía del Derecho de la Unión y la interpretación que el propio Tribunal ofrece desde Luxemburgo:

Por una parte, el principio general de no discriminación por razón de la edad, tal como lo concreta la Directiva 2000/78, debe interpretarse en el sentido de que, también en un litigio entre particulares, se opone a la normativa danesa en virtud de la cual un trabajador no puede percibir una indemnización por despido si tiene derecho a una pensión de jubilación pagada por su empresario con arreglo a un plan de pensiones al que se ha 
incorporado antes de cumplir 50 años, con independencia de si opta por permanecer en el mercado de trabajo o por jubilarse.

Y, por otra parte, corresponde al juez danés, que conoce de un litigio entre particulares comprendido en el ámbito de aplicación de la Directiva 2000/78, cuando aplica su Derecho nacional, interpretarlo de manera que pueda aplicarse de conformidad con dicha Directiva o, si tal interpretación conforme es imposible, dejar inaplicados, en caso necesario, cualesquiera preceptos del Derecho nacional que sean contrarios al principio general de no discriminación por razón de la edad. Ni los principios de seguridad jurídica o de protección de la confianza legítima, ni la posibilidad de que el particular que se considere lesionado por la aplicación de una norma nacional contraria al Derecho de la Unión reclame la responsabilidad del Estado miembro de que se trate por infracción del Derecho de la Unión permiten cuestionar dicha obligación de interpretación conforme.

\subsection{Los derechos de los consumidores}

La protección del consumidor ha sido un ámbito especialmente afectado por la reglamentación europea. Sin perjuicio de la intervención de las autoridades administrativas, las relaciones entre los consumidores y las empresas siguen siendo relaciones de Derecho privado.

Precisamente, en la sentencia Ruijssenaars y otros (C-145/15 y C-146/15) el Consejo de Estado neerlandés planteaba la cuestión de si la autoridad administrativa a la que se refiere el Reglamento (CE) n. ${ }^{\circ}$ 261/2004 sobre compensación y asistencia a los pasajeros aéreos en caso de denegación de embarque y de cancelación o gran retraso de los vuelos está obligada a adoptar medidas coercitivas contra un transportista aéreo con el fin de obligarle al pago de una compensación.

El Tribunal de Justicia recuerda que las reclamaciones de los pasajeros ante la autoridad administrativa deben considerase más bien denuncias con las que se contribuye a la correcta aplicación del Reglamento en general, sin que dicho organismo esté obligado a actuar a raíz de estas reclamaciones con el fin de garantizar el derecho de cada pasajero individual a obtener una compensación. En este sentido, el organismo administrativo tiene una misión de supervisión de carácter general pero no hay obligación de que adopte medidas coercitivas para los casos concretos.

Esto no le impide al Tribunal de Justicia subrayar que las disposiciones del Reglamento 261/2004 resultan directamente aplicables, y, en consecuencia, pueden invocarse ante los órganos jurisdiccionales nacionales en un litigio entre particulares, con lo que se garantiza la tutela judicial efectiva de los pasajeros aéreos. 
En consecuencia, el consumidor no podrá confiar en que las autoridades administrativas resuelvan el problema de la reclamación individual por lo que el consumidor deberá hacerla valer ante los jueces civiles nacionales.

En la sentencia Radlinger y Radlingerová (C-377/14) el Tribunal de Justicia se pronuncia a petición del Tribunal regional de Praga sobre la interpretación de la Directiva 93/13/CEE sobre las cláusulas abusivas en los contratos celebrados con consumidores y de la Directiva 2008/48/CE relativa a los contratos de crédito al consumo en relación con un procedimiento concursal.

El litigio tiene su origen en un contrato de crédito al consumo de unos 43.000 euros firmado por un matrimonio que se comprometió a devolver en 120 mensualidades, lo que suponía unos 109.000 euros, es decir, con un TAE cercano al $30 \%$. De hecho, en menos de un mes la financiera ya les exigió el pago de 106.300 euros.

En primer lugar, el Tribunal de Justicia llega a la conclusión de que la legislación checa es contraria a la Directiva 93/13/CEE en la medida en que no permite que el juez concursal examine de oficio el carácter eventualmente abusivo de las cláusulas contractuales de las que se derivan los créditos, aunque este juez disponga de los datos de hecho y de Derecho necesarios para ello, y dado que sólo permite que dicho juez examine los créditos que no vayan acompañados de una garantía, y ello únicamente en relación con un número limitado de alegaciones basadas en la prescripción o en la extinción de tales créditos.

En segundo lugar, el Tribunal de Justicia considera que la Directiva 2008/48/CE impone al juez checo la obligación de examinar de oficio si se cumple la obligación de información establecida en dicha disposición y de deducir las consecuencias previstas en el Derecho checo para el caso de incumplimiento de tal obligación.

Al preguntarle sobre el efecto directo de estas dos Directivas, el Tribunal de Justicia subraya que la obligación de proceder a un examen de oficio del carácter abusivo de ciertas cláusulas y de la presencia de las menciones obligatorias en un contrato de crédito constituye una norma procesal que no recae sobre los particulares sino sobre las autoridades judiciales. Y esto le basta para recordar su jurisprudencia sobre la interpretación conforme del Derecho nacional respecto del Derecho de la Unión.

Por último, el tribunal checo le pide orientación al Tribunal de Justicia sobre cómo actuar cuando los abusos del acreedor resultaban a todas luces ilegales. A tal efecto, el Tribunal de Justicia insiste en que los jueces nacionales están obligados únicamente a dejar sin aplicación la cláusula contractual abusiva, a fin de que no produzca efectos vinculantes para el con- 
sumidor, sin estar facultados para modificar el contenido de la misma, pero también indica que el contrato debe poder subsistir, en principio, sin otra modificación que la resultante de la supresión de las cláusulas abusivas, en la medida en que, en virtud de las normas del Derecho interno, ese mantenimiento del contrato sea jurídicamente posible.

\subsection{La contratación pública y la libre competencia}

La Gran Sala se pronuncia en la sentencia Puligienica Facility Esco (PFE) (C-689/13) a requerimiento Tribunal administrativo de apelación siciliano sobre la inadmisibilidad de un recurso contra la adjudicación de un contrato de servicios.

Previamente, el Tribunal de Justicia, al adoptar la sentencia Fastweb (C-100/12, EU:C:2013:448), consideró que el recurso incidental del adjudicatario no podía llevar a descartar el recurso de un licitador rechazado en el supuesto de que la regularidad de la oferta de cada uno de los operadores fuese cuestionada en el mismo procedimiento.

Y también en este caso el Tribunal de Justicia terminó subrayando que la Directiva 89/665 se oponía a que se inadmitiese un recurso principal interpuesto por un licitador que tenga un interés en obtener un contrato determinado y que se haya visto perjudicado por una supuesta vulneración del Derecho de la Unión en materia de contratos públicos.

En la sentencia DHL Express (Italy) (C-428/14) el Tribunal de Justicia, a requerimiento del Consejo de Estado italiano, insiste en que la Red Europea de la Competencia, integrada por autoridades nacionales de competencia y la Comisión, fomenta la discusión y la cooperación a la hora de aplicar la política de competencia pero no está facultada para adoptar normas jurídicamente vinculantes.

Por tanto, los instrumentos adoptados en el ámbito de la Red Europea de la Competencia, como es el caso del programa modelo sobre clemencia, no tienen efectos imperativos para las autoridades nacionales de competencia.

\subsection{La protección del medio ambiente}

La sentencia Grüne Liga Sachsen (C-399/14) se refiere a un litigio planteado ante el Tribunal Supremo Contencioso-administrativo de Alemania que debía interpretar la evaluación de impacto ambiental y su relación con la Directiva 92/43/CEE sobre la conservación de los hábitats naturales y de la fauna y flora silvestres (Directiva hábitats).

La obra cuya evaluación era objeto de controversia consistía en la construcción de un puente sobre el río Elba a su paso por Dresde que se aprobó 
como proyecto pero después la zona se incluyó en una lista LIC (Lugar de Interés Comunitario).

En primer lugar, el Tribunal de Justicia recuerda que, según su jurisprudencia, aunque un proyecto haya sido aprobado antes de que fuera aplicable en ese lugar el régimen de protección establecido en la Directiva «hábitats» $\mathrm{y}$, por tanto, ese proyecto no estuviera sujeto a las disposiciones reguladoras del procedimiento de evaluación previa de esta Directiva, la ejecución de tal proyecto queda comprendida dentro del ámbito de aplicación de la Directiva y debe ser objeto de un control a posteriori.

En segundo lugar, el Tribunal de Justicia determina el alcance de la evaluación a posteriori, es decir, debe tener en cuenta todos los elementos existentes en el momento de la inclusión del indicado lugar en la lista de los LIC, así como todas las repercusiones producidas o que pudieran producirse sobre el referido lugar después de esa fecha a raíz de la ejecución parcial o total de ese plan o de ese proyecto.

En tercer lugar, también el Tribunal de Justicia insiste en que las exigencias de un control ejercido en el marco de tal evaluación no pueden modificarse por el hecho de que la resolución por la que se aprobó el proyecto fuera directamente ejecutiva, no hubiera prosperado un procedimiento de medidas provisionales y esa resolución desestimatoria ya no fuera recurrible.

Sobre el particular, el Tribunal de Justicia puntualiza que el coste económico de las alternativas, incluida la demolición de la obra ya ejecutada, no tiene la misma importancia que el objetivo de conservación de los hábitats naturales y de la fauna y flora silvestres que persigue la Directiva hábitats.

La sentencia Borealis Polyolefine (C-191/14, C-192/14, C-295/14, C-389/14 y C-391/14 a C-393/14) responde sendas preguntas planteadas por el Consejo de Estado neerlandés, el Tribunal Regional de lo Contencioso-Administrativo de la Baja Austria y el Tribunal administrativo regional italiano del Lacio en relación con la validez de la asignación gratuita de derechos de emisión de gases de efecto invernadero contenida en una decisión de la Comisión Europea.

La primera cuestión planteada al Tribunal de Justicia versó sobre la legitimación para la impugnación indirecta de actos o disposiciones de las instituciones europeas, es decir, se planteó la aplicación de la conocida como jurisprudencia Deggendorf, construida a partir de la sentencia TWD Textilwerke Deggendorf (C-188/92, EU:C:1994:90).

El propio Tribunal de Justicia recuerda su criterio conforme al cual: «la posibilidad de que un justiciable alegue ante el órgano jurisdiccional nacional al que ha recurrido la invalidez de disposiciones contenidas en actos de la Unión presupone que dicha parte no hubiera dispuesto del de- 
recho a interponer un recurso directo contra esas disposiciones». En el caso concreto, aunque las recurrentes en los procedimientos judiciales nacionales son titulares de instalaciones generadoras de emisiones de gases de efecto invernadero, las decisiones europeas controvertidas no tienen en cuenta su situación individual. Por tanto, el Tribunal de Justicia accede al examen de la cuestión de validez de las dos decisiones controvertidas.

En cuanto a la Decisión 2011/278, el Tribunal de Justicia considera que la asimetría que supone la exclusión de las emisiones relativas a la producción de electricidad con gases residuales y calor en la cogeneración de calor y electricidad es conforme con la Directiva 2003/87/CE por la que se establece un régimen para el comercio de derechos de emisión de gases de efecto invernadero. A juicio del Tribunal de Justicia, a pesar de la distinción clara que se hace entre los generadores de electricidad y las instalaciones industriales, estas últimas pueden recibir gratuitamente derechos de emisión para determinadas emisiones que estén vinculadas a la producción de electricidad. No obstante, dichas emisiones no se tendrán en cuenta al calcular la cantidad máxima anual de derechos de emisión.

En cambio, el Tribunal de Justicia anula la Decisión 2013/448 porque la Comisión, al establecer la cantidad máxima anual de derechos de emisión, debía tener en cuenta únicamente las emisiones de las instalaciones incluidas en el régimen comunitario a partir de 2013, sin poder tener en cuenta las emisiones generadas por determinadas actividades desde 2013, puesto que dichas emisiones fueron producidas por instalaciones sujetas ya antes de esa fecha al régimen de comercio de derechos de emisión. Por tanto, la Comisión no fijó la cantidad máxima anual de derechos de emisión de conformidad con la Directiva 2003/87.

A petición de la Comisión Europea, el Tribunal de Justicia limitó temporalmente los efectos de la anulación de la Decisión 2013/448, de modo que, por una parte, dicha declaración únicamente surtirá efectos tras un plazo de diez meses desde que se dictó la sentencia, el 28 de abril de 2016, con el fin de permitir que la Comisión pueda adoptar las medidas necesarias y de modo que, por otra parte, no puedan impugnarse las medidas que hasta que termine dicho plazo se hayan adoptado de conformidad con las disposiciones anuladas.

\section{Segunda parte. La jurisprudencia europea provocada por los jueces españoles y sus efectos en el derecho interno}

Ya de manera más exhaustiva expongo las resoluciones adoptadas por el Tribunal de Justicia en relación con España, en particular, en respuesta a 
cuestiones prejudiciales más algunos ejemplos significativos de sentencias dictadas en recursos de incumplimiento seguidos contra España.

\section{Las sentencias prejudiciales «españolas»}

En 2015 y según las estadísticas del Informe del Tribunal de Justicia desde España se formularon 36 cuestiones prejudiciales y en los treinta años desde la adhesión ya van 390 cuestiones prejudiciales, a una media de 13 reenvíos prejudiciales por año.

Estas dos cifras contrastan notablemente porque se ha pasado de una escasa implicación europea de los jueces españoles a un activismo judicial de gran interés. En este sentido, la preocupación inicial por el escaso atrevimiento de los jueces españoles provocó que en 2006 el Consejo General del Poder Judicial, bajo el impulso del recordado abogado general Dámaso RuizJarabo, crease la Red de Expertos en Derecho de la Unión Europea (REDUE).

Esta red de jueces y para jueces está integrada desde entonces por 10 jueces en ejercicio, dos por cada orden jurisdiccional (civil, mercantil, penal, contencioso-administrativo y social) y su objetivo es crear un entorno más propicio y facilitar la cooperación de los jueces españoles con el Tribunal de Justicia.

Las cifras de los últimos años parecen muy alentadoras para proseguir esta tarea. Asimismo, algunas de las cuestiones prejudiciales han sido especialmente exitosas en provocar una jurisprudencia prodigiosa como ha sido, sin duda, la referida a las cláusulas abusivas.

Si pudiésemos medir el éxito valdría con señalar que la vista del Tribunal de Justicia, en su composición de Gran Sala, del 26 de abril de 2016 despertó la atención inusitada de los medios de comunicación españoles. En esta vista se abordaron las cuestiones planteadas por el Juzgado de lo Mercantil n..$^{\circ} 1$ de Granada y la Audiencia Provincial de Alicante (asuntos C-154/15, C-307/15 y C-308/15, Gutiérrez Naranjo, Palacios Martínez y Banco Popular Español) sobre los efectos ex nunc o ex tunc de la anulación de las cláusulas suelo por la sentencia, de 9 de mayo de 2013, de la Sala de lo Civil del Tribunal Supremo.

Las posturas, como revelan los asuntos C-307/15 y C-208/15, son contradictorias: de los dos asuntos de los que conocía en apelación la Audiencia en ambos casos estimaron las demandas a la vista de la sentencia del Tribunal Supremo y anularon las cláusulas de este tipo pero en el asunto C-307/15 la nulidad de la «cláusula suelo» sólo tenía efecto retroactivo a partir de la fecha de esa sentencia del Tribunal Supremo, mientras que en el asunto C-308/15, el juez de instancia declaró, como punto de partida de los efectos de la nulidad de esta cláusula, la fecha de la celebración del contrato 
de préstamo hipotecario controvertido. En el otoño de 2016 se espera que el Tribunal de Justicia zanje la cuestión.

\subsection{Las respuestas sobre cláusulas abusivas: sentencias y autos}

El Tribunal de Justicia se pronunció a requerimiento de los tribunales españoles en cuatro resoluciones sobre las cláusulas abusivas: el auto Ibercaja Banco (C-613/15), el auto Garzón Ramos y Ramos Martín (C-380/15), la sentencia Finanmadrid (C-49/14) y la sentencia Sales Sinués (C-381/14 y C-385/14).

En primer lugar, con el auto Ibercaja Banco el Tribunal de Justicia se pronunció a requerimiento del Juzgado de Primera Instancia $n^{\circ} 5$ de Alcobendas que le había pedido la interpretación de la Directiva 93/13/CEE sobre cláusulas abusivas en los contratos celebrados con los consumidores en relación con la Ley Hipotecaria y la Ley de Enjuiciamiento Civil.

La Ley Hipotecaria solo permite al juez, para valorar el carácter abusivo de una cláusula que fija los intereses de demora, comprobar si el tipo de interés pactado supera tres veces el tipo de interés legal y no otras circunstancias. La Ley de Enjuiciamiento Civil permite reclamar de forma anticipada la totalidad del préstamo por incumplimiento de tres cuotas mensuales, sin tener en cuenta otros factores como la duración o la cuantía del préstamo o cualesquiera otras causas concurrentes relevantes y, además, condiciona la posibilidad de evitar los efectos de dicho vencimiento anticipado a la voluntad del acreedor salvo en los casos de hipoteca que grave la vivienda habitual del deudor.

El Tribunal de Justicia explica que el carácter abusivo de una cláusula contractual deberá apreciarse teniendo en cuenta la naturaleza de los bienes o servicios que sean objeto del contrato y tomando en consideración en el momento de su celebración todas las circunstancias que concurran. Esto supone, conforme a la jurisprudencia europea, que incumbe a los tribunales nacionales apreciar el carácter abusivo de las cláusulas contractuales y deducir todas las consecuencias que, según el Derecho nacional, se derivan de ello, a fin de evitar que estas cláusulas vinculen al consumidor. Esta es una disposición imperativa que pretende reemplazar el equilibrio formal que el contrato establece entre los derechos y las obligaciones de las partes por un equilibrio real que pueda restablecer la igualdad entre éstas. En definitiva y a juicio del Tribunal de Justicia, las previsiones cuestionadas de la Ley Hipotecaria y de la Ley de Enjuiciamiento Civil son contrarias a la Directiva.

En segundo lugar, la sentencia Finanmadrid EFC es la respuesta a la cuestión prejudicial del Juzgado de Primera Instancia n. ${ }^{\circ} 5$ de Cartagena sobre la interpretación de la Directiva 93/13/CEE y el artículo 47 de la Carta en relación con el proceso monitorio. 
En su enjuiciamiento, el Tribunal de Justicia comprueba que el desarrollo y las particularidades del proceso monitorio español son tales que, cuando no concurran las circunstancias que determinan la intervención del juez este concluye sin que pueda realizar un control de la existencia de cláusulas abusivas en un contrato celebrado entre un profesional y un consumidor. En consecuencia, si el juez que conoce de la ejecución del requerimiento de pago carece de competencia para apreciar de oficio la existencia de esas cláusulas, podría hacerse valer un título ejecutivo frente al consumidor sin que, en ningún momento del procedimiento, tenga la garantía de que se ha llevado a cabo esa apreciación.

Esto determina que la normativa española relativa al sistema de aplicación del principio de cosa juzgada en el marco del proceso monitorio no sea conforme con el principio de efectividad, en la medida que hace imposible o excesivamente difícil, en los litigios iniciados a instancia de los profesionales y en los que los consumidores son parte demandada, aplicar la protección que la Directiva 93/13 pretende conferir a estos últimos.

Sin embargo, el Tribunal de Justicia rechaza por infundada la pregunta relativa a la vulneración del derecho a la tutela judicial efectiva consagrada en el artículo 47 de la Carta.

En tercer lugar, con la sentencia Sales Sinués el Tribunal de Justicia responde al Juzgado de lo Mercantil $n .^{\circ} 9$ de Barcelona sobre la interpretación de la Directiva 93/13/CEE en relación con las acciones colectivas.

El Tribunal de Justicia distingue entre acciones individuales y acciones colectivas. Respecto de las primeras señala que el sistema de protección que establece la Directiva 93/13 se basa en la idea de que el consumidor se halla en situación de inferioridad respecto al profesional, tanto en lo relativo a la capacidad de negociación como al nivel de información. En cambio, respecto de las acciones ejercitadas por personas u organizaciones a las que se reconoce un interés legítimo en la protección de los consumidores, estos sujetos no se encuentran en tal situación de inferioridad respecto a los profesionales.

Esto significa, a juicio del Tribunal de Justicia, que las acciones individuales y colectivas tienen, en el marco de la Directiva 93/13, objetos y efectos jurídicos diferentes, de modo que la relación de índole procesal entre la tramitación de las unas y las otras únicamente puede atender a exigencias de carácter procesal asociadas, en particular, a la recta administración de la justicia y que respondan a la necesidad de evitar resoluciones judiciales contradictorias, sin que la articulación de esas diferentes acciones deba conducir a una merma de la protección de los consumidores, tal como está prevista en la Directiva 93/13.

Así pues, la Directiva 93/13 es incompatible con la regulación procesal española que obliga al juez que conoce de una acción individual de un con- 
sumidor, dirigida a que se declare el carácter abusivo de una cláusula de un contrato que le une a un profesional, a suspender automáticamente la tramitación de esa acción en espera de que exista sentencia firme en relación con una acción colectiva que se encuentra pendiente, ejercitada por una asociación de consumidores con el fin de que cese el uso, en contratos del mismo tipo, de cláusulas análogas a aquella contra la que se dirige dicha acción individual, sin que pueda tomarse en consideración si es pertinente esa suspensión desde la perspectiva de la protección del consumidor que presentó una demanda judicial individual ante el juez y sin que ese consumidor pueda decidir desvincularse de la acción colectiva.

En fin, el auto Garzón Ramos y Ramos Martín inadmite la petición de decisión prejudicial planteada por la Audiencia Provincial de les Illes Balears. Se refiere a la interpretación de cláusulas abusivas y su control por el juez en un procedimiento de ejecución hipotecaria. La pregunta pretende la interpretación a la luz únicamente del artículo 47 de la Carta de los Derechos Fundamentales de la Unión Europea, que consagra el derecho a la tutela judicial efectiva, sin apoyarse en el Derecho derivado, en la Directiva sobre cláusulas abusivas.

Sin embargo, el Tribunal de Justicia, quizás de modo un poco estricto, termina señalando que el auto de remisión no contiene dato alguno que permita considerar que el objeto del litigio principal se refiere a la interpretación o a la aplicación de una norma del Derecho de la Unión diferente de las recogidas en la Carta.

\subsection{La cooperación judicial civil y la traducción de los documentos: auto Alta Realitat}

El Juzgado de Primera Instancia n. ${ }^{\circ} 44$ de Barcelona le planteó al Tribunal de Justicia una cuestión prejudicial relativa al Reglamento (CE) n. ${ }^{\circ} 1393 / 2007$ sobre notificación y traslado de documentos civiles y mercantiles en relación con una demanda remitida desde España a Dinamarca, redactada en inglés y que el demandado se había negado a aceptar alegando que no conocía tal lengua y a pesar de que todos los indicios apuntaban que utilizaba ese idioma con fluidez. El Juzgado de Barcelona consideró que tal negativa no estaba justificada y dictó una sentencia estimatoria que devino firme. No obstante, en ejecución de sentencia los jueces daneses se negaron a reconocerla por lo que el Juzgado de Barcelona anuló la sentencia. El Tribunal de Justicia consideró que esta cuestión prejudicial era sencilla y la resolvió con el auto Alta Realitat (C-384/14).

Después de invocar los principios básicos de la cooperación judicial civil (su finalidad es el buen funcionamiento del mercado interior y pretende mejorar la eficacia y rapidez de los procedimientos judiciales y asegurar la 
buena administración de justicia, respetando el derecho de defensa), el Tribunal de Justicia recuerda cómo funciona el procedimiento de notificación de documentos: por una parte, incumbe al organismo transmisor comunicar al requirente que el destinatario puede negarse a aceptar el documento por no estar redactado en una de las lenguas previstas en el Reglamento; y, por otra parte, corresponde en principio al requirente asumir los gastos de traducción previos a la transmisión del documento.

Asimismo, el Tribunal de Justicia explica que el papel del organismo transmisor y el del organismo receptor se limita a garantizar materialmente el traslado de los documentos así como a adoptar medidas que puedan facilitar el desarrollo de tales operaciones, pero no tienen competencia alguna para pronunciarse sobre cuestiones de naturaleza sustantiva, como la de qué lenguas entiende el destinatario del documento y la de si el documento debe ir acompañado o no de una traducción. Por tanto, corresponde exclusivamente al tribunal nacional que conoce del asunto en el Estado miembro de origen pronunciarse sobre las cuestiones sustantivas cuando el demandante y el demandado discrepen sobre ellas.

El Tribunal de Justicia recuerda la importancia y la obligatoriedad de utilizar los formularios normalizados como instrumentos mediante los que se informa a los destinatarios de su facultad de negarse a aceptar el documento notificado. Precisamente, una de las principales innovaciones introducidas, con el fin de mejorar la transmisión de los documentos y de garantizar una mejor protección al destinatario, es la posibilidad de que el destinatario del documento, en caso de que se niegue a aceptar dicho documento por no estar redactado en una lengua que él entienda o por no ir acompañado de una traducción, indique la lengua que entiende. Por eso, cuando el organismo receptor realiza el traslado de un documento a su destinatario está obligado, en todos los supuestos, a adjuntar el formulario normalizado recogido en el Reglamento n. ${ }^{\circ} 1393 / 2007$ que informa al destinatario de su derecho a negarse a aceptar ese documento y es el juez que conoce del asunto en el Estado miembro de origen quien debe velar por el respeto de tales normas.

Asimismo, el derecho a negarse a aceptar un documento notificado deriva de la necesidad de proteger el derecho de defensa del destinatario, conforme a las exigencias de un proceso equitativo y es, una vez que el destinatario ha ejercido ese derecho, el juez que conoce del asunto el que podrá pronunciarse válidamente sobre la procedencia de esa negativa. El juez deberá tomar debidamente en consideración toda la información pertinente que obre en autos a fin de determinar si el destinatario que se negó a aceptar el documento podía comprenderlo y hacer valer eficazmente sus derechos o si, habida cuenta de la naturaleza de dicho documento, se requería su traducción. Para el caso de que el juez concluya que está justificada la negativa del 
destinatario procederá la notificación de una traducción apropiada. En caso de que constate que la negativa del destinatario del documento no estaba justificada, el juez de origen podrá, en principio, aplicar las consecuencias establecidas en su Derecho nacional para ese supuesto, siempre que se preserve el efecto útil del Reglamento n. ${ }^{\circ}$ 1393/2007 o lo que es lo mismo: una vez que se haya asegurado de que el interesado recibió real y efectivamente el escrito de demanda, que tuvo conocimiento del procedimiento judicial iniciado contra él y que se identificó el objeto y la causa de la demanda y dispuso de tiempo suficiente para preparar su defensa. En todo caso la resolución judicial en la que se declare injustificada esa negativa debe ser firme.

\subsection{El blanqueo de capitales y la financiación del terrorismo: sentencia Safe Interenvíos}

La Audiencia Provincial de Barcelona le preguntó al Tribunal de Justicia sobre la interpretación de la Directiva 2005/60/CE relativa a la prevención de la utilización del sistema financiero para el blanqueo de capitales y para la financiación del terrorismo.

Ante el tribunal catalán se enfrenta la empresa Safe Interenvíos a tres bancos que habían cancelado sus cuentas por sospechar que blanqueaban capitales. Safe acudió al Juzgado de lo Mercantil de Barcelona que, aun cuando consideró que la actuación de los bancos estaba justificada, decidió que habían incurrido en competencia desleal por no haber expuesto las razones que justificaban tales medidas.

En su contestación en la sentencia Safe Interenvíos (C-235/14) el Tribunal de Justicia responde, por una parte, que la Directiva no se opone a una legislación como la española que permite la aplicación de medidas normales de diligencia debida con respecto a los clientes cuando estos son entidades financieras cuyo cumplimiento de las medidas de diligencia debida es objeto de supervisión si existen sospechas de blanqueo de capitales o de financiación del terrorismo; y, por otra parte, el Tribunal de Justicia obliga a las entidades y personas sujetas a la Directiva a aplicar, en función de su apreciación del riesgo, medidas reforzadas de diligencia debida con respecto al cliente en aquellas situaciones que, por su propia naturaleza, puedan presentar un riesgo más elevado de blanqueo de capitales o de financiación del terrorismo, como el envío de fondos.

Y, al mismo tiempo, la Directiva permite a los Estados miembros adoptar o mantener en vigor disposiciones más estrictas, siempre que tengan como finalidad reforzar la lucha contra el blanqueo de capitales o la financiación del terrorismo.

En su sentencia el Tribunal de Justicia distingue claramente entre las obligaciones de diligencia debida con respecto al cliente y de declaración 
que incumben a las entidades de crédito y las medidas de supervisión y control que corresponde adoptar a las autoridades nacionales competentes. Se trata de un conjunto de medidas preventivas y disuasorias para luchar eficazmente contra el blanqueo de capitales y la financiación del terrorismo y para garantizar la solidez y la integridad del sistema financiero.

Ahora bien, el Tribunal de Justicia llega a la conclusión de que una normativa como la española, que tiene por objeto luchar contra el blanqueo de capitales y la financiación del terrorismo, persigue un objetivo legítimo capaz de justificar una restricción de las libertades fundamentales y aunque el hecho de presuponer que las transferencias de fondos por parte de una entidad sujeta a la citada Directiva a Estados miembros distintos de aquel en que se halla establecida presentan siempre un riesgo más elevado de blanqueo de capitales o de financiación del terrorismo es adecuado para garantizar la realización de dicho objetivo, esta normativa excede de lo necesario para alcanzar el objetivo que persigue, en la medida en que la presunción que establece se aplica a todas las transferencias de fondos, sin contemplar la posibilidad de destruir esa presunción en el caso de transferencias de fondos que objetivamente no presentan tal riesgo.

La última pregunta que hacía la Audiencia Provincial de Barcelona se refería a la interpretación de la Directiva sobre datos personales aplicable cuando las entidades de pagos deban facilitar los datos de sus clientes a las entidades de crédito con las que están forzadas a operar y con las que a la vez compiten en el mercado. Sin embargo, esta pregunta no fue admitida por el Tribunal de Justicia porque el juez español no había señalado cuál era el problema interpretativo y dado que en realidad nunca estuvieron en juego cuestiones relativas a datos personales.

\subsection{La compensación equitativa por los derechos de autor en el caso de copias privadas: sentencia EGEDA}

El Tribunal de Justicia ha dictado la sentencia EGEDA (C-470/14) en respuesta a un reenvío prejudicial de la Sala de lo Contencioso-administrativo del Tribunal Supremo sobre la interpretación de la Directiva 2001/29/ CE sobre derechos de autor en lo que se refiere al derecho a la compensación por copia privada tal como se había regulado en España.

Tres entidades de gestión colectiva de derechos de propiedad intelectual (EGEDA, DAMA y VEGAP) cuestionaron la conformidad con la Directiva del nuevo sistema, introducido en 2011, de compensación equitativa por copia privada con cargo a los presupuestos generales del Estado, tal como fue desarrollado por el Real Decreto 1657/2012. Con el nuevo sistema, por ejemplo para 2014 se habían destinado cinco millones de euros a esta com- 
pensación (véase la Orden ECD/2226/2015 del Ministerio de Cultura español), las entidades de gestión se veían particularmente perjudicadas.

La Directiva 2001/29 permite que los Estados miembros establezcan limitaciones al derecho exclusivo de reproducción de los titulares de los derechos de autor en el caso de las reproducciones en cualquier soporte efectuadas por una persona física para uso privado y sin fines directa o indirectamente comerciales siempre que los titulares de los derechos reciban una compensación equitativa.

A juicio del Tribunal de Justicia, esta excepción de copia privada se concibió en beneficio exclusivo de las personas físicas y, por tanto, las personas jurídicas no pueden acogerse a esta excepción, de modo que no están facultadas para efectuar copias privadas sin obtener la autorización previa de los titulares de los derechos sobre las obras o prestaciones de que se trate.

En el caso de optar por establecer esta excepción, como fue el caso de España, hay una obligación de regular el abono de una «compensación equitativa» a favor de los titulares de los derechos que podría hacerse incluso a través de un sistema de compensación equitativa financiado a través de los presupuestos públicos.

En España el sistema de la compensación por copia privada sustituyó al que con anterioridad, también para incorporar la Directiva 2001/29, había establecido la Ley de Propiedad Intelectual desde 1996 denominado «canon digital» y que indirectamente ya se había cuestionado a raíz de la sentencia Padawan (C 467/08, EU:C:2010:620) del mismo Tribunal de Justicia.

Ahora bien, en el régimen español, impugnado ante el Tribunal Supremo, no se asegura, según el Tribunal de Justicia, que el coste de la compensación equitativa sea soportado por los usuarios de copias privadas al sufragar los presupuestos generales todos los contribuyentes, incluidas las personas jurídicas que no pueden incluirse en la excepción controvertida.

En suma, la sentencia EGEDA pone de manifiesto que el sistema español de compensación por copia privada no es conforme con la Directiva en la medida en que no puede garantizar que el coste de la compensación, asumida por los presupuestos generales del Estado, sea sufragado, en último término y únicamente, por los usuarios de copias privadas.

\subsection{El alcance de la indemnización por vulneración de la propiedad intelectual: sentencia Liffers}

El Tribunal Supremo solicitó del Tribunal de Justicia que interpretase la Directiva 2004/48/CE relativa al respeto de los derechos de propiedad intelectual, en particular, si entre los daños indemnizables se incluyen los daños morales. 
En este caso se trataba de un productor cubano que exigía a Telecinco los daños y perjuicios, incluidos los morales, por la inserción sin su permiso y en un reportaje de televisión de una obra audiovisual de su propiedad.

El Tribunal de Justicia en la sentencia Liffers (C-99/15) llega a la conclusión de que la Directiva 2004/48 no incluye el daño moral como elemento que las autoridades judiciales han de tener en cuenta cuando fijan la indemnización que ha de abonarse al titular del derecho pero tampoco excluye que se tenga en cuenta este tipo de daños.

En efecto, esta disposición, al prever la posibilidad de fijar un importe a tanto alzado de la indemnización por daños y perjuicios «cuando menos» sobre la base de los elementos que en él se mencionan, permite incluir en dicho importe otros elementos como, en su caso, la indemnización del daño moral causado al titular de dicho derecho.

Asimismo, el Tribunal de Justicia insiste en que la Directiva 2004/48 tiene por objetivo garantizar un nivel de protección de la propiedad intelectual elevado, equivalente y homogéneo en el mercado interior. De lo que deduce un principio conforme al cual el cálculo del importe de la indemnización que ha de abonarse al titular de un derecho de propiedad intelectual debe tener por objeto garantizar la reparación íntegra del perjuicio «efectivamente sufrido», teniendo por referencia, por ejemplo, la base de licencias hipotéticas, pero también incluyendo en su caso el posible daño moral causado.

\subsection{La prueba de medios de subsistencia en la agrupación familiar de extranjeros: sentencia Khachab}

La Sala de lo Contencioso-administrativo del Tribunal Superior de Justicia del País Vasco preguntó al Tribunal de Justicia si la interpretación de la Directiva 2003/86/CE sobre el derecho a la reagrupación familiar era compatible con el Reglamento español de extranjería que prevé la denegación de la reagrupación si se determina indubitadamente que no existe, en relación con el residente extranjero y reagrupante, una perspectiva de mantenimiento de los medios económicos durante el año posterior a la fecha de presentación de la solicitud.

En la sentencia Khachab (C-558/14) el Tribunal de Justicia subraya que la Directiva 2003/86 tiene por objetivo facilitar la integración de los nacionales de terceros países en los Estados miembros, permitiéndoles llevar una vida familiar gracias a la reagrupación familiar.

Ahora bien, la Directiva 2003/86 restringe su ámbito de aplicación personal al reagrupante que haya obtenido un permiso de residencia de al menos un año y que tenga una perspectiva fundada de obtener un permiso de residencia permanente. Por tanto, la evaluación de la existencia de tal perspectiva 
exige necesariamente que la autoridad pública realice un examen de la evolución futura de la situación del reagrupante en relación con la obtención de dicho permiso de residencia. Y también, de acuerdo con la Directiva, la autoridad nacional puede retirar la autorización de reagrupación familiar cuando el reagrupante ya no disponga de recursos fijos y regulares suficientes.

Por esa razón, el Tribunal de Justicia considera que de la jurisprudencia del Tribunal de Justicia se desprende que la Directiva 2003/86 exige que se realice un examen individualizado de las solicitudes de reagrupación familiar y que las autoridades nacionales competentes, al examinar las solicitudes de reagrupación familiar, deben proceder a una apreciación equilibrada y razonable de todos los intereses en juego.

\subsection{La dimensión medioambiental de las ayudas europeas a la agricultura: sentencia Planes Bresco}

El Tribunal de Justicia ha dictado la sentencia Planes Bresco (C-333/15 y C-334/15, EU:C:2016:426) en dos asuntos pendientes ante la Sala de lo Contencioso-administrativo del Tribunal Supremo que enfrentan a una agricultora, Pilar Planes Bresco, con el Gobierno de Aragón por la reducción de unas ayudas financiadas por los fondos europeos.

Los litigios tienen su origen en la determinación de cuantía de las ayudas concedidas por la Comunidad Autónoma de Aragón para las campañas 2007 y 2008 . En aplicación del Reglamento n. ${ }^{\circ}$ 1782/2003 el Gobierno aragonés había previsto que las superficies consideradas para calcular las ayudas incluyesen los pastos permanentes para la alimentación del ganado de la explotación. El Tribunal Superior de Justicia de Aragón consideró que esta exigencia autonómica era conforme con el Derecho de la Unión. No obstante, en casación el Tribunal Supremo reclamó la interpretación del Tribunal de Justicia.

El interés de la sentencia radica en la dimensión medioambiental que, según la interpretación del Tribunal de Justicia, corresponde a los agricultores de acuerdo con la nueva política agrícola europea y que tiene su traducción en la financiación europea canalizada en este caso a través de la Administración aragonesa.

El Tribunal de Justicia llega a la conclusión de que las superficies de pastos permanentes de una explotación agraria son admisibles a efectos de calcular la ayuda por superficie en la medida en que formen parte de la superficie agraria de dicha explotación, y su mantenimiento en buenas condiciones agrarias y medioambientales constituye en sí mismo una actividad agraria, sin que sea relevante el hecho de que las gramíneas y otros forrajes herbáceos no se utilicen directamente para las necesidades específicas de la explotación agraria relacionadas con la cría de ganado. 
A juicio del Tribunal de Justicia, esta interpretación queda corroborada por el hecho de que los pastos permanentes tienen un efecto medioambiental positivo y resulta oportuno adoptar medidas para fomentar su mantenimiento y evitar una transformación masiva en tierras de cultivo.

En suma, de la sentencia Planes Bresco se deduce que la normativa aragonesa, al restringir la cuantía de las ayudas por el hecho de que los pastos permanentes no se dedicasen a alimentar el ganado, no es conforme con el Derecho de la Unión Europea que configura la ayuda controvertida.

\subsection{La indemnización por despido discriminatorio entre mujeres y hombres: sentencia Arjona Camacho}

La petición de decisión prejudicial del Juzgado de lo Social n.$^{\circ} 1$ de Córdoba fue respondida por la sentencia Arjona Camacho (C-407/14) por la que el Tribunal de Justicia interpreta la Directiva 2006/54/CE relativa a la aplicación del principio de igualdad de oportunidades e igualdad de trato entre hombres y mujeres en asuntos de empleo y ocupación.

La trabajadora María Auxiliadora Arjona Camacho había sido despedida por el hecho de ser mujer y el juez le planteó al Tribunal de Justicia si podía acordar una indemnización disuasoria a pesar de que tal concepto no existía en el Derecho español. El juez cordobés adelantó claramente el sentido de su sentencia al considerar que frente a los 6.000 euros de indemnización que pedía la trabajadora despedida, el importe de 3.000 euros en concepto de indemnización de daños y perjuicios bastaba para reparar íntegramente el perjuicio sufrido. Sin embargo, preguntaba si procedía acordar una indemnización disuasoria o punitiva para servir de escarmiento al antiguo empleador de la trabajadora y a otros empresarios.

El Tribunal de Justicia subraya que la Directiva, adoptada para ajustarse a su propia jurisprudencia, exige que se adopten las medidas apropiadas para restablecer la igualdad efectiva de oportunidades, debe garantizar una tutela judicial efectiva y eficaz y surtir un efecto disuasorio real frente al empresario. No obstante, su artículo 25 permite pero no impone a los Estados miembros adoptar medidas que establezcan el abono de daños punitivos a la víctima de una discriminación por razón de sexo.

Esto significa que si el Derecho español no lo prevé el juez no puede condenar por sí mismo al autor de esta discriminación al abono de tales daños. Y aun suponiendo que un Estado miembro decide adoptar medidas que permitan conceder daños punitivos a la persona discriminada, incumbe al ordenamiento jurídico interno de cada Estado miembro fijar los criterios que permitan establecer el alcance de la sanción, siempre que se respeten los principios de equivalencia y efectividad. 
En definitiva, para que el perjuicio sufrido como consecuencia de una discriminación por razón de sexo sea efectivamente indemnizado de manera disuasoria y proporcionada, la Directiva 2006/54/CE obliga a los Estados miembros que elijan la forma pecuniaria a introducir en su ordenamiento jurídico interno con el fin de asegurar el pago de una indemnización que cubra íntegramente dicho perjuicio a la persona que haya sufrido un perjuicio.

\subsection{Los permisos parental y de maternidad de los cooperativistas: sentencia Rodríguez Sánchez}

La sentencia Rodríguez Sánchez (C-351/14) es una respuesta a varias cuestiones planteadas por el Juzgado de lo Social n. ${ }^{\circ} 33$ de Barcelona sobre la interpretación de la Directiva 2010/18/UE que aplica el Acuerdo marco revisado sobre el permiso parental. Se trataba de un litigio de una socia trabajadora en la red de supermercados de la cooperativa Consum donde trabaja de cajera. Después de su permiso de maternidad, Estrella Rodríguez Sánchez solicitó la reducción de jornada y el cambio de turnos y la adaptación de horarios, accediendo su cooperativa únicamente a la reducción de la jornada.

Para decidir sobre la admisibilidad de las cuestiones prejudiciales, el Tribunal de Justicia distingue entre el permiso de maternidad («que consiste en asegurar la protección de la condición biológica de la mujer y las especiales relaciones entre la mujer y su hijo durante el período que sigue al embarazo y al parto, evitando que la acumulación de cargas que deriva del ejercicio simultáneo de una actividad profesional perturbe dichas relaciones») y el permiso parental («que se concede a los padres para que puedan ocuparse de su hijo y puede accederse a él hasta los ocho años del hijo»).

El Tribunal de Justicia llegó a la conclusión de que la Directiva 2010/18 no se aplicaba al caso concreto dado que solo regula las situaciones de reincorporación al trabajo tras un «permiso parental» pero no puede interpretarse en el sentido de que cubra una situación de reincorporación tras un «permiso de maternidad». Esto es lo que le lleva al Tribunal de Justicia a inadmitir el reenvío prejudicial.

Ahora bien, la singularidad de la sentencia es que ilustra sobre las relaciones entre el juez nacional y el Tribunal de Justicia durante el procedimiento prejudicial. En este caso, fue el Tribunal de Justicia, después del reenvío prejudicial, el que pidió aclaraciones al Juzgado barcelonés que se las remitió en forma de auto de 13 de julio de 2015. Pero, además, a la vista de las Conclusiones del abogado general Szpunar, de 3 de marzo de 2016, el juez de Barcelona volvió a remitir un nuevo auto de 16 de marzo de 2016. 
Sin embargo, sobre este modo de actuar del Juez catalán, el Tribunal de Justicia recuerda, en primer lugar, que ni el Estatuto del Tribunal de Justicia de la Unión Europea ni el Reglamento de Procedimiento prevén la posibilidad de que las partes o el juez remitente presenten observaciones en respuesta a las conclusiones presentadas por el Abogado General, dado que solo el Tribunal de Justicia puede solicitar aclaraciones al juez nacional.

Y, en segundo lugar, el Tribunal de Justicia subraya que el espíritu de colaboración que debe presidir el funcionamiento de la remisión prejudicial supone que, por su parte, el juez nacional tenga en cuenta la función confiada al Tribunal de Justicia, que es la de contribuir a la administración de justicia en los Estados miembros y no la de formular opiniones consultivas sobre cuestiones generales o hipotéticas.

Probablemente el Tribunal de Justicia haya sido demasiado estricto inadmitiendo el reenvío prejudicial pero no hay duda de que no le ha gustado nada que el juez nacional pretenda dirigir el procedimiento prejudicial, especialmente pronunciándose y corrigiendo las Conclusiones del abogado general que, por lo demás, había sido más comprensivo y había contestado las cuestiones planteadas sin necesidad de proponer la inadmisión del reenvío prejudicial.

\section{Las nuevas cuestiones prejudiciales «españolas» pendientes en el Tribunal de Justicia}

También en el primer semestre de 2016 la inquietud de los jueces españoles se ha sentido en Luxemburgo donde se han recibido numerosas cuestiones prejudiciales cuyo examen revela que se enzarzan unas con otras como si fuesen cerezas.

Así ha ocurrido en el caso de las cláusulas abusivas y también se observa en relación con la Directiva sobre contratos de duración determinada en el empleo público y la aplicación del régimen europeo de ayudas de Estado aplicado a los tributos autonómicos y locales.

En estos casos es preciso recordar que los jueces, por prudencia, deben ponderar la posibilidad de suspender hasta que se resuelvan tales cuestiones prejudiciales. Así lo ha hecho, con particular pundonor, la Sala de lo Civil del Tribunal Supremo que, a pesar de cuestionarse su propia jurisprudencia sobre los efectos de la anulación de las cláusulas suelo, suspendió la tramitación de un recurso de casación relativo precisamente a un litigio muy similar al que había sido el origen de una cuestión prejudicial planteada por el Juzgado de lo Mercantil n. ${ }^{\circ} 1$ de Granada.

En virtud de su auto de 12 de abril de 2016 (recurso n. ${ }^{\circ}$ 2367/2014, ES:TS:2016:2927A, ponente: Saraza Jimena) la Sala de lo Civil del Tribu- 
nal Supremo suspendió la tramitación del recurso de casación «hasta la resolución de la cuestión prejudicial planteada ante el Tribunal de Justicia de la Unión Europea (C-154/15)».

\subsection{La Directiva sobre contratos de duración determinada y sus efectos en el empleo público español}

Como continuación de previas sentencias prejudiciales del Tribunal de Justicia, el Juzgado de lo Contencioso-administrativo n. ${ }^{\circ} 1$ de Oviedo ha plantado dos interesantísimas cuestiones prejudiciales referidas a la Directiva 1999/70/CE relativa al Acuerdo marco sobre el trabajo de duración determinada que podrían tener una importante repercusión en el empleo público español.

En estos momentos en España numerosísimos funcionarios interinos pretenden, de la misma manera que ocurrió con el cobro de los trienios, equipararse con los funcionarios de carrera en la percepción del incentivo de la carrera profesional. En el asunto C-631/15, Álvarez Santirso, el juez ovetense pregunta si es conforme con la Directiva que protege al personal temporal, incluidos los empleados públicos, la Ley asturiana 6/2009 de evaluación de la función pública docente y sus incentivos, que exige, para poder ser incluido en el Plan de evaluación (y por ende percibir los incentivos económicos ligados a ello), tener la condición de funcionario de carrera lo que, por tanto, excluye a los funcionarios interinos.

En el asunto C-158/16, Vega González, el mismo juez asturiano plantea también si la Directiva sobre el trabajo de duración determinada protege a una funcionaria interina, con más de cuatro años de antigüedad, que fue elegida parlamentaria regional y que solicitó el reconocimiento a la Administración autonómica asturiana de la situación administrativa de servicios especiales o, subsidiariamente, de excedencia voluntaria. Aun cuando la Administración del Principado de Asturias le denegó la declaración de excedencia voluntaria por no ser funcionaria de carrera, la pretensión de la funcionaria interina es que, de acuerdo con la protección conferida por la Directiva, una vez que termine su situación como parlamentaria autonómica, pueda volver al puesto que ocupaba interinamente si es que sigue vacante.

\subsection{El régimen de ayudas de Estado y el cuestionamiento de los tributos autonómicos y locales}

En el ámbito de los tributos autonómicos y locales, el régimen europeo de ayudas de Estado está teniendo una especial incidencia como revelan las recientes cuestiones prejudiciales planteadas por jueces españoles siguiendo la estela de la sentencia Navantia (C-522/13, EU:C:2014:2262). 
La sentencia Navantia ha tenido un efecto reflejo en otros jueces españoles, incluido el Tribunal Supremo, que han cuestionado algunos tributos autonómicos y locales invocando el incumplimiento del régimen europeo de ayudas de Estado.

Ahora bien, tales cuestionamientos no resultan pacíficos y su aplicación, como revela el propio asunto Navantia, añade una gran complejidad y una cierta confusión a un régimen que, sin duda, debe aplicarse con total transparencia.

En efecto, a raíz de la sentencia Navantia, el Juzgado de lo Contenciosoadministrativo de Ferrol desestimó, por sentencia de 8 de enero de 2015, el recurso del Ministerio de Defensa, apoyado por Navantia, contra la liquidación municipal que no le aplicaba la exención en el Impuesto de Bienes Inmuebles por considerar que tal exención constituía una ayuda de Estado.

En cambio, el Tribunal Superior de Justicia de Galicia, en virtud de su sentencia de 16 de julio de 2015, revocó la sentencia del juez ferrolano e impuso su criterio, invocando al Tribunal Supremo y reconociendo la exención tributaria en favor del Ministerio de Defensa y, en consecuencia, de Navantia (Sala C-A, recurso n. ${ }^{\circ}$ 15049/15, ES:TSJGAL:2015:5832, ponente: Gómez y Díaz-Castroverde). A tal efecto, el tribunal gallego concluyó su resolución terciando en estos términos: «la sentencia del TJUE, sobre el particular, formuló consideraciones de carácter general favorables a la infracción del artículo 107.1 TFUE; pero reservando la decisión correspondiente al criterio del Juez sobre el particular por lo cual, ya para finalizar, aquella declaración de carácter general no puede, sin más, proyectarse a la sentencia y, menos aún, conducir a la denegación de la exención que corresponde al Estado».

Con posterioridad llegaron al Tribunal de Justicia varias cuestiones prejudiciales según las cuales el régimen de ayudas de Estado también afectaría a determinados tributos autonómicos y municipales.

Por un parte, el Juez de lo Contencioso-administrativo n. ${ }^{\circ} 1$ de Tarragona le había planteado al Tribunal de Justicia (C 302/15) si el impuesto municipal de construcciones, instalaciones y obras, en este caso por un importe de 1.482,88 euros, exigido a Correos y Telégrafos por el Ayuntamiento de Vila Seca podía considerarse conforme con el régimen de ayudas de Estado y con la Directiva 2008/6/CE sobre servicios postales comunitarios. No obstante y como consecuencia del desistimiento en el procedimiento principal, el Tribunal de Justicia archivó el asunto por auto de 9 de marzo de 2016 (ECLI:EU:C:2016:192).

Por otra parte, el Juez de lo Contencioso-administrativo n. ${ }^{\circ} 4$ de Madrid también le ha preguntado al Tribunal de Justicia, en un asunto que enfrenta a la Congregación de Escuelas Pías Provincia Betania con el Ayuntamiento de Getafe (C-74/16), sobre la compatibilidad con el régimen de 
ayudas de Estado de la exención aplicada a la Iglesia Católica del impuesto sobre construcciones, instalaciones y obras respecto de las obras en inmuebles destinados al desarrollo de actividades económicas que no tienen una finalidad estrictamente religiosa.

De un modo mucho más claro y preciso, el Tribunal Supremo ha planteado cinco cuestiones prejudiciales (C-233/16 a C-237/16) en sendos asuntos que enfrentan a la Asociación Nacional de Grandes Empresas de Distribución (ANGED) con las Comunidades Autónomas de Aragón, Asturias y Cataluña respecto del impuesto sobre grandes establecimientos comerciales por cuanto las legislaciones autonómicas gravan a unas empresas pero no a otras por lo general de menores dimensiones o dedicadas a determinadas actividades comerciales.

El Tribunal Supremo plantea si la exención a los pequeños negocios es conforme con el derecho de establecimiento y con el régimen de ayudas de Estado. Por una parte, el Tribunal Supremo pregunta si la existencia de un impuesto regional que grava el funcionamiento únicamente de grandes establecimientos comerciales es conforme con las libertades económicas fundamentales. Por otra parte, el Tribunal Supremo se apoya en el régimen de ayudas de Estado para cuestionar si, por ejemplo, la no sujeción al IGEC asturiano de los establecimientos comerciales que no sean grandes constituye una ayuda de Estado.

\section{Los incumplimientos medioambientales de España}

El recurso por incumplimiento constituye un procedimiento ante el Tribunal de Justicia particularmente interesante para conocer el grado de adaptación de los derechos nacionales al Derecho de la Unión.

España no es, desde luego, el más significativo de los incumplidores, dado que la palma se la lleva Italia y en proporción a su tamaño destacan Grecia y Bélgica, pero en los últimos 30 años la Comisión Europea ha llevado en 244 ocasiones a España ante el Tribunal de Justicia pidiendo que la condene por incumplir el Derecho de la Unión.

Lo habitual es que el procedimiento termine con una condena: por ejemplo, de 2011 a 2015, los recursos por incumplimiento fueron 23 de los cuales todos terminaron con sentencia condenatoria salvo uno. En el caso de España el ámbito más propicio a las condenas es el medioambiental. Precisamente en lo que va de 2016 ya se han dictado dos sentencias que declaran que España incumple el Derecho de la Unión.

En primer lugar, el Tribunal de Justicia tiene que recordar a golpe de sentencia que España incumple la Directiva 1999/31/CE relativa al vertido de residuos al tolerar o no cumplir las exigencias de los vertederos. 
La sentencia de 25 de febrero de 2016 condena nuevamente a España por no cerrar los vertederos ilegales (C-454/14). El razonamiento del Tribunal de Justicia no podía ser más obvio: «la obligación de asegurar que sólo los vertederos que cumplan las exigencias de la Directiva 1999/31 sigan funcionando también implica el cierre de las instalaciones que no hayan obtenido la autorización para continuar sus operaciones». En este sentido el Tribunal de Justicia señala el incumplimiento por parte de España de la Directiva debido a la existencia de numerosos vertederos localizados en el País Vasco, Islas Canarias, Aragón, Murcia y Andalucía.

Es cierto que el procedimiento de infracción se inició en 2009 pero todo parece conducir inexorablemente a una sanción por inejecución de sentencia que, a la vista de los antecedentes de nuestro país, podría ser considerable. De hecho, no se entiende, como demuestra el pavoroso incendio del vertedero de neumáticos en Seseña que llegó a verse desde Madrid el 13 de mayo de 2016, tanta incuria de las administraciones españolas y que tan graves consecuencias puede tener para la salud física y económica de un país bastante maltrecho.

$\mathrm{Y}$ en segundo lugar, lo mismo se puede decir del tratamiento de aguas residuales urbanas a la vista de la sentencia de 10 de marzo de 2016 (C38/15) en virtud de la cual el Tribunal de Justicia condena nuevamente a España por incumplir la Directiva 91/271/CEE.

La constatación del incumplimiento se hace respecto de las aglomeraciones de Berga, Figueres y El Terri (Banyoles) en Cataluña y PontevedraMarín-Poio-Bueu en Galicia. El procedimiento precontencioso lo inició la Comisión Europea en 2003 pero también los antecedentes en el incumplimiento de esta Directiva 92/271 son a todas luces calamitosos y preocupantes.

\section{Relación de las sentencias comentadas (Tribunal de Justicia y Tribunal General)}

1. TJ, sentencia de 17 de diciembre de 2015, Arjona Camacho (C-407/14, EU:C:2015:831) (despido discriminatorio e indemnización disuasoria).

2. TJ, sentencia de 14 de enero de 2016, Grüne Liga Sachsen (C-399/14, EU:C:2016:10) (evaluación medioambiental de proyectos).

3. TJ, sentencia de 20 de enero de 2016, DHL Express (C-428/14, EU:C:2016:27) (libre competencia en el sector del transporte internacional de mercancías).

4. TJ (Gran Sala) sentencia de 15 de febrero de 2016, J. N. (C-601/15 PPU, EU:C:2016:84) (solicitantes de protección internacional, permanencia legal e internamiento). 
5. TJ, sentencia de 18 de febrero de 2016, Finanmadrid (C-49/14, EU:C:2016:98) (cláusulas abusivas y proceso monitorio).

6. TJ, auto de 23 de febrero de 2016, Garzón Ramos (C-380/15, EU:C:2016:112) (ejecución hipotecaria e incompetencia del Tribunal de Justicia).

7. TJ, sentencia de 25 de febrero de 2016 , Jovanna García-Nieto y otros (C-299/14, EU:C:2016:114) (ciudadanía de la Unión y prestaciones no contributivas durante los tres primeros meses de residencia).

8. TJ, sentencia de 25 de febrero de 2016, Comisión / España (C-454/14, EU:C:2016:117) (incumplimiento de la Directiva 1999/31/CE sobre vertido de residuos).

9. TJ, sentencia de 25 de febrero de 2016, Liffers (C-99/15, EU:C:2016:173) (indemnización de daños morales por vulneración de la propiedad intelectual).

10. TJ (Gran Sala), sentencia de 1 de marzo de 2016, Kreis Warendorf y otros (C-443/14 y C-444/14, EU:C:2016:127) (protección de refugiados).

11. TJ, auto de 9 de marzo de 2016, Correos y Telégrafos (C-302/15, EU:C:2016:192) (Directiva de servicio público universal y ayudas de Estado: desistimiento).

12. TJ, sentencia de 10 de marzo de 2016, Safe Interenvíos (C-235/14, EU:C:2016:154) (blanqueo de capitales y obligaciones de la entidades bancarias).

13. TJ, sentencia de 10 de marzo de 2016, Comisión / España (C-38/15, EU:C:2016:156) (tratamiento de las aguas residuales urbanas).

14. TJ, sentencia de 17 de marzo de 2016, Benallal (C-161/15, EU:C:2016:175) (motivo de impugnación en casación y derechos de los ciudadanos de la Unión).

15. TJ, sentencia de 17 de marzo de 2016 , K. Ruijssenaars y otros (C-145/15 y C-146/15. EU:C:2016:187) (compensación por cancelación de vuelos).

16. TJ, sentencia de 17 de marzo de 2016, Mirza (C-695/15 PPU, EU:C:2016:188) (readmisión de un solicitante de asilo).

17. TJ, auto de 17 de marzo de 2016, Ibercaja Banco SAU / José Cortés González (C-613/15, EU:C:2016:195) (cláusulas abusivas y poderes del juez).

18. TJ (Gran Sala), sentencia de 5 de abril de 2016, Pál Aranyosi y Robert Căldăraru (C-404/15 y C-659/15 PPU, EU:C:2016:198) (euroorden y riesgo de trato inhumano en prisiones húngaras y rumanas).

19. TJ (Gran Sala) sentencia de 5 de abril de 2016, Puligienica Facility Esco PFE (C-689/13, EU:C:2016:199) (contratos públicos de servicios y procedimientos de recurso). 
20. TJ (Gran Sala), sentencia de 12 de abril de 2016, Caner Genc (C561/14. EU:C:2016:247) (reagrupación familiar de nacionales turcos).

21. TJ, sentencia de 14 de abril de 2016, Sales Sinués y Drame Ba (C381/14 y C-385/14, EU:C:2016:252) (cláusulas abusivas, acciones individuales y acciones colectivas).

22. TJ (Gran Sala) sentencia de 19 de abril de 2016, DI (C-441/14, EU:C:2016:278) (no discriminación por razón de la edad en el trabajo).

23. TJ, sentencia de 21 de abril de 2016, Radlinger (C-377/14, EU:C:2016:283) (procedimientos concursales y protección del consumidor frente a cláusulas abusivas).

24. TJ, sentencia de 21 de abril de 2016, Khachab (C-558/14, ECLI:EU:C:2016:285) (reagrupación familiar de nacional de país tercero).

25. TJ, sentencia de 28 de abril de 2016, Borealis Polyolefine (C-191/14, C-192/14, C-295/14, C-389/14 y C-391/14 a C-393/14, EU:C:2016:311) (derechos de emisión de gases de efecto invernadero).

26. TJ, auto de 28 de abril de 2016, Alta Realitat (C-384/14, EU:C:2016:316) (cooperación judicial civil y falta de traducción del documento trasladado).

27. TJ, sentencia de 25 de mayo de 2016, Rudolfs Meroni / Recoletos Limited (C-559/14, EU:C:2016:349) (tutela judicial efectiva y cooperación judicial civil).

28. TJ, sentencia de 24 de mayo de 2016, Dworzecki (C-108/16 PPU, EU:C:2016:346) (euroorden y garantías del procedimiento penal).

29. TJUE (Gran Sala), sentencia de 7 de junio de 2016, Affum (C-47/15, EU:C:2016:408) (pena de prisión por entrada irregular en Francia).

30. TJUE (Gran Sala), sentencia de 7 de junio de 2016, Ghezelbash (C-63/15, EU:C:2016:409) (sistema de asilo y tutela judicial de los extranjeros).

31. TJUE (Gran Sala), sentencia de 7 de junio de 2016, Karim (C-155/15, EU:C:2016:410) (control judicial de la determinación del Estado miembro responsable de examinar la petición de asilo).

32. TJUE, sentencia de 9 de junio de 2016, EGEDA y otros (C-470/14, EU:C:2016:418) (compensación equitativa por copia privada con cargo al presupuesto del Estado).

33. TJUE, sentencia de 9 de junio de 2016, Planes Bresco (C-333/15 y C-334/15, EU:C:2016:426) (pastos permanentes admisibles a efectos de las ayudas agrarias y dimensión medioambiental).

34. TJUE, sentencia de 16 de junio de 2016, Rodríguez Sánchez (C351/14, EU:C:2016:447) (permiso de maternidad y permiso parental de los trabajadores). 


\section{Derechos de autor (Copyright)}

Los derechos de autor (distribución, comunicación pública, reproducción e inclusión en bases de datos de indexación y repositorios institucionales) de esta publicación pertenecen a la editorial Universidad de Deusto. El acceso al contenido digital de cualquier número de Cuadernos Europeos de Deusto (CED) es gratuito, transcurridos 6 meses desde su publicación. Los trabajos podrán descargarse, copiar y difundir, sin fines comerciales y según lo previsto por la ley. Así mismo, los trabajos editados en CED pueden ser publicados con posterioridad en otros medios o revistas, siempre que el autor indique con claridad y en la primera nota a pie de página que el trabajo se publicó por primera vez en CED, con indicación del número, año, páginas y DOI (si procede). 